\title{
EBSD analysis of subgrain boundaries and dislocation slip systems in Antarctic and Greenland ice
}

\author{
Ilka Weikusat ${ }^{1}$, Ernst-Jan N. Kuiper ${ }^{1,2}$, Gill M. Pennock ${ }^{2}$, Sepp Kipfstuhl ${ }^{1}$, and Martyn R. Drury ${ }^{2}$ \\ ${ }^{1}$ Alfred Wegener Institute Helmholtz Centre for Polar and Marine Research, Am Alten Hafen 26, \\ 27568 Bremerhaven, Germany \\ ${ }^{2}$ Faculty of Earth Science, Utrecht University, Postbus 80021, 3508 TA Utrecht, the Netherlands \\ Correspondence to: Ilka Weikusat (ilka.weikusat@awi.de)
}

Received: 1 February 2017 - Discussion started: 24 February 2017

Revised: 7 July 2017 - Accepted: 8 July 2017 - Published: 6 September 2017

\begin{abstract}
Ice has a very high plastic anisotropy with easy dislocation glide on basal planes, while glide on non-basal planes is much harder. Basal glide involves dislocations with the Burgers vector $\boldsymbol{b}=\langle\boldsymbol{a}\rangle$, while glide on non-basal planes can involve dislocations with $\boldsymbol{b}=\langle\boldsymbol{a}\rangle, \boldsymbol{b}=[\boldsymbol{c}]$, and $\boldsymbol{b}=\langle\boldsymbol{c}+$ $a\rangle$. During the natural ductile flow of polar ice sheets, most of the deformation is expected to occur by basal slip accommodated by other processes, including non-basal slip and grain boundary processes. However, the importance of different accommodating processes is controversial. The recent application of micro-diffraction analysis methods to ice, such as X-ray Laue diffraction and electron backscattered diffraction (EBSD), has demonstrated that subgrain boundaries indicative of non-basal slip are present in naturally deformed ice, although so far the available data sets are limited. In this study we present an analysis of a large number of subgrain boundaries in ice core samples from one depth level from two deep ice cores from Antarctica (EPICA-DML deep ice core at $656 \mathrm{~m}$ of depth) and Greenland (NEEM deep ice core at $719 \mathrm{~m}$ of depth).

EBSD provides information for the characterization of subgrain boundary types and on the dislocations that are likely to be present along the boundary. EBSD analyses, in combination with light microscopy measurements, are presented and interpreted in terms of the dislocation slip systems. The most common subgrain boundaries are indicative of basal $\langle\boldsymbol{a}\rangle$ slip with an almost equal occurrence of subgrain boundaries indicative of prism $[\boldsymbol{c}]$ or $\langle\boldsymbol{c}+\boldsymbol{a}\rangle$ slip on prism and/or pyramidal planes. A few subgrain boundaries are indicative of prism $\langle\boldsymbol{a}\rangle$ slip or slip of $\langle\boldsymbol{a}\rangle$ screw dislocations on the basal plane. In addition to these classical polygoniza-
\end{abstract}

tion processes that involve the recovery of dislocations into boundaries, alternative mechanisms are discussed for the formation of subgrain boundaries that are not related to the crystallography of the host grain.

The finding that subgrain boundaries indicative of nonbasal slip are as frequent as those indicating basal slip is surprising. Our evidence of frequent non-basal slip in naturally deformed polar ice core samples has important implications for discussions on ice about plasticity descriptions, rate-controlling processes which accommodate basal glide, and anisotropic ice flow descriptions of large ice masses with the wider perspective of sea level evolution.

\section{Introduction}

Ice, particularly the extensive amounts found in the polar ice sheets, impacts the global climate directly by changing the albedo and indirectly by supplying an enormous water reservoir that affects sea level change (IPCC, 2014, 2007; Stocker et al., 2010; Lemke et al., 2007; Bindoff et al., 2007). The discharge of material into the oceans is controlled by the melt excess over snow accumulation and the dynamic flow of ice (Hock, 2005). Fast discharge by ice streams up to several hundred metres per year in surface velocity (Joughin et al., 2015) includes the rapid transportation of ice towards coasts by sliding over the bedrock due to various subglacial processes (Vaughan and Arthern, 2007; Hughes, 2009; Thoma et al., 2010; Beem et al., 2010; Wolovick and Creyts, 2016) and the flow of material towards these rapid ice streams by internal deformation of the whole ice body. Internal deforma- 
tion is therefore responsible for the required convergent flow geometries at the onset of ice streams (Bons et al., 2016), although at only a few centimetres to metres per year.

Ice sheet flow models (e.g. Greve and Blatter, 2009; Huybrechts, 2007) are based on Glen's flow law (Glen, 1955). This power-law was derived from the experimental deformation of small ice specimens at higher stresses $(0.1$ to $1 \mathrm{MPa})$ than occur in ice sheet flow $(<0.1 \mathrm{MPa})$. The flow-limiting processes for different flow conditions are a matter of extensive discussion and include contributions from various deformation mechanisms, such as dislocation creep and grainboundary sliding limited-basal slip. In addition, the flow properties are influenced by crystallographic preferred orientation (CPO), recrystallization, and the occurrence of second phases (impurities, air, or a liquid phase; Alley, 1992; Alley et al., 2005; Goldsby and Kohlstedt, 1997, 2001; Duval and Montagnat, 2002; Song, 2008; Schulson and Duval, 2009; Steinbach et al., 2016; Eichler et al., 2017).

The main deformation process in the creep deformation of natural ice is presumed to be intra-crystalline dislocation glide in combination with climb recovery into subgrain boundary planes (e.g. Schulson and Duval, 2009; Faria, 2014b). This is supported by the occurrence of strong caxis CPO and evidence of extensive dynamic recrystallization (e.g. Duval and Montagnat, 2002; Weikusat et al., 2009; Kipfstuhl et al., 2009; Faria et al., 2014b). Knowledge of dislocation activity and the types of dislocation involved, preferably along the length of an ice core, is therefore of importance for a complete understanding of ice deformation in ice sheets and glaciers.

Ice found on Earth is hexagonal, and dislocation activity along basal (0001) versus prismatic $\{h 0 \bar{i} 0\}$ and pyramidal $\{h 0 \bar{i} l\}$ planes is highly anisotropic. Critical resolved shear stresses on non-basal planes require 60 to 100 times higher stresses than activating dislocation glide on basal planes (Duval et al., 1983; Ashby and Duval, 1985), so slip on basal planes is expected to dominate. Non-basal slip has been observed by X-ray topography in ice single crystals (e.g. Fukuda and Higashi, 1969; Fukuda et al., 1987; Higashi et al., 1988; Baker, 2003), although only as short segments that are not expected to contribute to the dominant macroscopic deformation (Shearwood and Whitworth, 1991). To date there is no direct evidence for slip on other non-basal planes in natural polycrystalline ice, in spite of the shortage of independent slip systems to deform ice only by basal slip (Hutchinson, 1977). Previous studies are mainly based on experimental deformation carried out under laboratory conditions on polycrystalline (Barrette and Sinha, 1994; Bryant and Mason, 1960; Wei and Dempsey, 1994; Breton et al., 2016) and/or single crystal ice (Montagnat et al., 2003, 2001). This study presents the first step in an ongoing study using naturally deformed ice from a single depth level of two deep ice cores from the large ice sheets. The possible dislocation types are derived from an analysis of the subgrain boundaries (SGBs) present in the ice using light microscopy and electron backscattered diffraction (EBSD).

Microstructure mapping using light microscopy (LM) of etched surfaces (Fig. 1) and automatic image processing tools were developed to study ice core samples (Kipfstuhl et al., 2006; Binder et al., 2013a; Weikusat et al., 2017b). Grain boundaries (GBs) and SGBs in ice are differentiated using LM images by the depth of thermally etched grooves (Mullins, 1957; Nishida and Narita, 1996; Arnaud et al., 1998; Barnes, 2003). SGBs have lower misorientation angles than GBs, so they form shallower etch grooves (Saylor and Rohrer, 1999; Gottstein and Shvindlerman, 1999) which have lower contrast than GBs in LM images and appear grey rather than black (Fig. 1a). Sublimation behaviour changes due to boundary property changes by intrinsic energy changes (e.g. Gottstein and Shvindlerman, 1999; Suzuki and Kuroiwa, 1972; Suzuki, 1970; Ketcham and Hobbs, 1969). In addition to contrast differences in the etched boundaries, the shape of the boundary was used to distinguish between SGBs and GBs: SGBs generally have straighter segments that are controlled by the recovery of dislocations and locally tend to fade out, whereas GBs tend to be smoothly curved and are continuous.

X-ray Laue diffraction (Weikusat et al., 2011) confirmed that the less deeply etched, straighter boundaries observed in LM (Weikusat et al., 2009b) all had low misorientation angles $<5^{\circ}$ and were SGBs. The SGBs in natural polar ice (Weikusat et al., 2009b; Kipfstuhl et al., 2009) and in deformed artificial ice (Hamann et al., 2007; Weikusat et al., 2009a) can be grouped into certain types according to the alignment of their intersection line (trace) with the etched surface. The SGB trace can be described with respect to the c-axis, or basal plane, using polarized LM. Four SGB types were identified (Fig. 1c, Weikusat et al., 2009b): the N-type SGB has a trace that is predominantly normal to the basal plane, the P-type has a trace parallel to the basal plane, the Z-type has an irregular zigzag trace with one orientation that is predominantly normal to the basal plane, and lastly, a SGB with no strong alignment to the basal plane which is often curved. The N-type SGB is also called the "Nakaya" type after the first extensive description in 1958 by Nakaya of low misorientation angle boundaries in ice occurring "in the prism plane ... perpendicular to the gliding layers" (Nakaya, 1958). This type of SGB resembles the classical perception that glaciologists have of an ice grain undergoing recovery and the polygonization of dislocations into a SGB (for example, Fig. 2 in Alley et al., 1995). The N-type SGB is usually deeply etched and cuts across the whole, or a large part, of the grain. Several N-type SGBs can cluster together with one or two fainter, shorter, sub-parallel SGBs. The P-type SGBs are also straight and often occur in parallel swarms that typically do not cross a grain, but fade out after a short distance. Z-type SGBs often appear in networks and intricate patterns that usually form short lengths that do not completely cross a grain. Z-type SGBs are typically less deeply etched and 

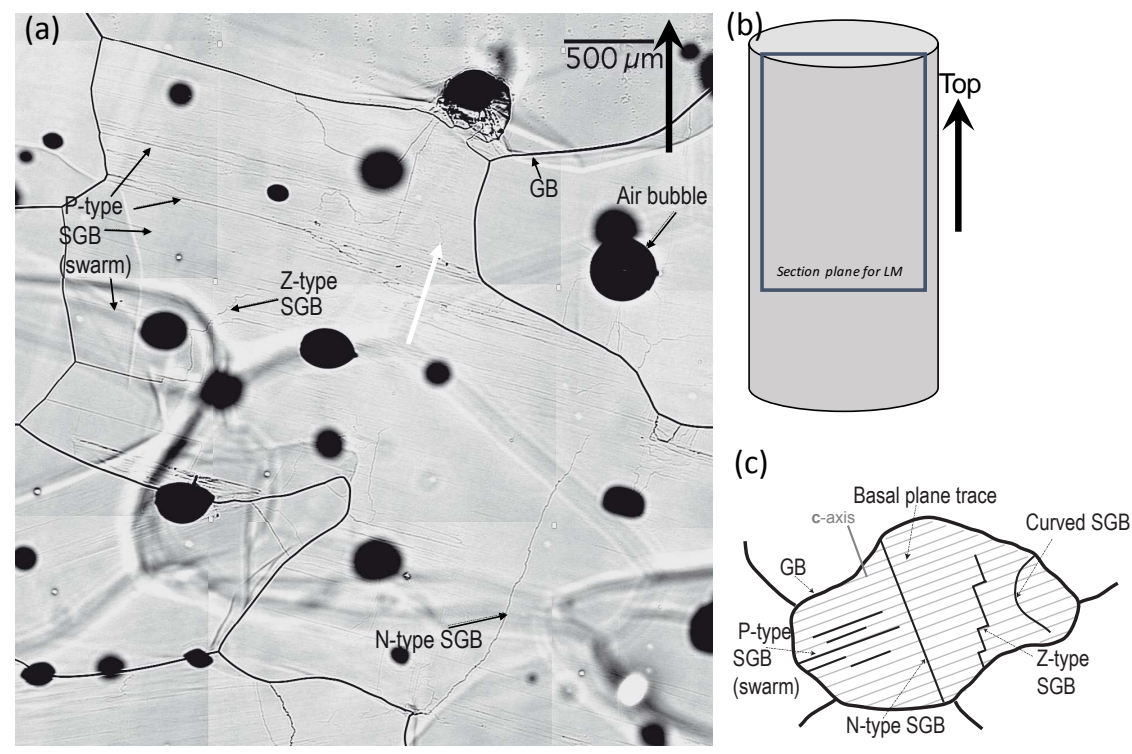

Figure 1. (a) Light microscopy (LM) image of the etched surface of EDML ice (depth $694 \mathrm{~m}$ ). The small black arrow shows different SGS types. The white arrow shows the trace of the c-axis. The large dark features are air bubbles in the ice. Features beneath the surface are out of focus and indistinct. GB is grain boundary and SGB is subgrain boundary. (b) Schematic diagram showing the orientation of sample sections in the ice core. The large black arrows $(\mathbf{a}, \mathbf{b})$ point towards the upper surface of the ice sheet. (c) Schematic diagram of the four types of SGBs described in the text (after Weikusat et al., 2009).

disappear towards the core of the grain. The curved SGB types are rarely observed, possibly because the surface orientation influences the sublimation (see method explanation in Weikusat et al., 2009b).

Based on LM mapping analysis along an ice core, the P-type SGB is the most frequent of all subgrain boundary types at all depths of the EDML ice core, followed by the Z-type, N-type, and curved types (Weikusat et al., 2009b). X-ray Laue diffraction (Weikusat et al., 2011) of approximately 240 shallow sublimation grooves revealed misorientation angles of less than $5^{\circ}$. Many $(30-40 \%)$ were below the angular resolution of $0.5^{\circ}$ for Laue, while the majority $(50-60 \%)$ were below $3^{\circ}$. Only a small percent had misorientation angles between 3 and $5^{\circ}$. From those SGBs found with misorientation angles $>0.5^{\circ}(165)$, analyses indicated that the formation of 45 of them involved significant nonbasal slip activity (Weikusat et al., 2011). Although X-ray Laue diffraction is a very useful technique for determining the slip system of a boundary in materials with a large grain size (e.g. natural ice), measurements and processing of Laue patterns are semi-automatic (Miyamoto et al., 2011) and thus time consuming. Only a limited number of boundaries could be measured. Identifying the proportion of non-basal dislocation activity is crucial for understanding the deformability of ice. Significant non-basal slip might cause a change in the deformation rate-controlling processes and lead to a change in the stress exponent from a value of 3 at low stresses towards 2 at higher stresses (Montagnat and Duval, 2000). To determine slip systems in a large number of SGBs, EBSD is needed.

Cryo-EBSD has been successfully used to study ice (Iliescu et al., 2014; Obbard et al., 2006). Maintaining a stable ice surface during EBSD assessment (Weikusat et al., 2011; Prior et al., 2015) is essential for these studies to allow for correlation between LM-etched surfaces and to differentiate between in situ deformation occurring in the ice sheet and any relaxation effects that occur during the various sample preparation procedures (Weikusat et al., 2010). When a subgrain boundary is formed by the polygonization of geometrically necessary dislocations (Humphreys and Hatherly, 2004; Weertman and Weertman, 1992; Hirth and Lothe, 1982), the crystallography (boundary plane and rotation axis) of subgrain boundaries can be interpreted in terms of the active dislocation slip systems. EBSD provides full crystallographic information (Randle and Engler, 2000) from which slip systems can be derived (Trepied et al., 1980; Neumann, 2000; Lloyd et al., 1997; Prior et al., 2002; Piazolo et al., 2008; Weikusat et al., 2011; Montagnat et al., 2015), although SGB plane traces are best obtained from the corresponding LM images to avoid any artefacts (Weikusat et al., 2011).

In this work we assess SGB types in two ice core samples from Antarctica and Greenland using LM and cryo-EBSD. We assess a single depth in each ice core. The boundary types are described using the same terminology as that used in our earlier LM studies. The slip systems from a significant number of boundaries in natural ice are inferred using EBSD so that we can assess the importance of non-basal slip activity 

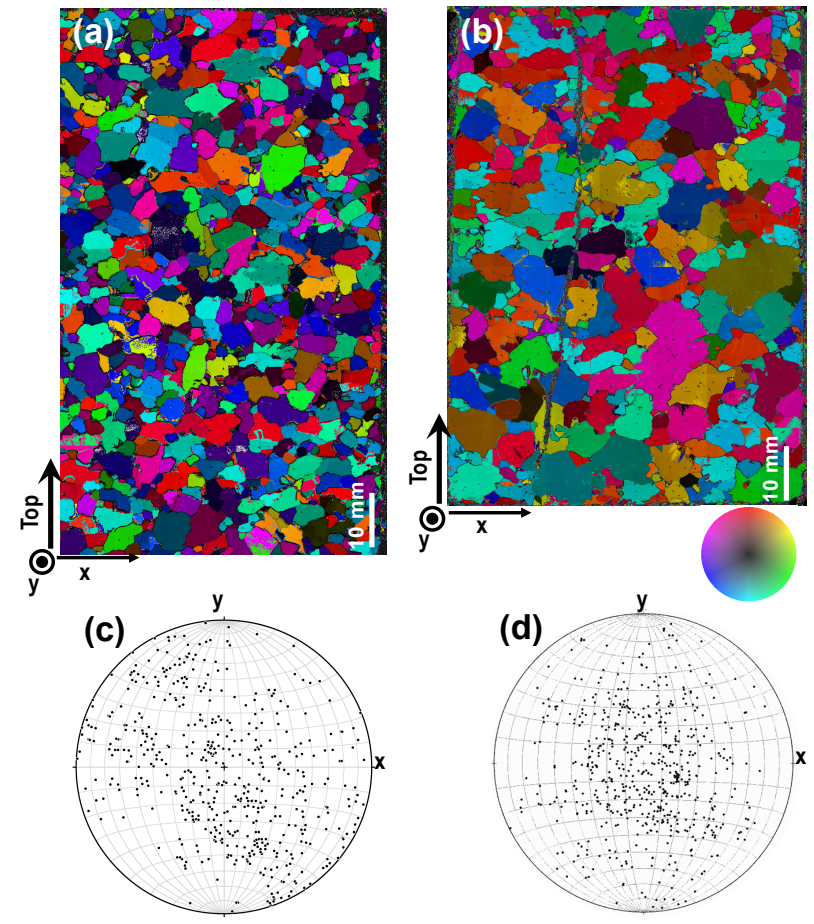

Figure 2. General appearance of the c-axis microstructure of (a) EDML microstructures at $655.5 \mathrm{~m}$ of depth and (b) NEEM at $718.2 \mathrm{~m}$ of depth. The orientation of the c-axes is shown by the coloured disc (the central grey colour indicates a c-axis that is vertical to the plane of the image). Panels (c) and (d) show pole figures of the c-axes for individual grains (one point per grain), 525 grains for the EDML sample and 601 grains in the NEEM sample. Please note that pole figure projection (equal area, lower hemisphere) follows the glaciological convention of looking down on the core axis (top) from above.

previously identified in a limited number of boundaries using combined X-ray and LM studies.

\section{Material and methods}

Samples from two polar ice cores were used for this study: NEEM (North Greenland Eemian Ice Drilling) and EDML (European Project for Ice Coring in Antarctica; Dronning Maud Land). We collected data on a single, roughly equivalent depth for each core in order to obtain a first comparable statistic of SGB type.

The EDML samples were obtained from $656 \mathrm{~m}$ of depth from the EPICA deep ice core drilled between 2003 to 2006 at Kohnen station $\left(75^{\circ} 00^{\prime} \mathrm{S}, 0^{\circ} 40^{\prime} \mathrm{E} ; 2892 \mathrm{~m}\right.$ a.s.l.) in the Atlantic sector of East Antarctica (Oerter et al., 2009; Ruth et al., 2007; Wilhelms et al., 2007, 2014). The NEEM samples were obtained from $719 \mathrm{~m}$ of depth and were drilled between 2008 and 2012 in north-western Greenland $\left(77^{\circ} 27^{\prime} \mathrm{N}\right.$, $51^{\circ} 03^{\prime} \mathrm{W}$; $2484 \mathrm{~m}$ a.s.l.; NEEM, 2013; Rasmussen et al., 2013). Both sample depths originated from snow deposited during the Holocene (Ruth et al., 2007; Rasmussen et al., 2013) and have comparably small impurity concentrations (e.g. Dansgaard et al., 1982; EPICA 2004, 2006; Kuramoto et al., 2011; Wegner et al., 2015). Both drill sites are located on ice ridges or ice divides with horizontal flow velocities at the surface of $0.8 \mathrm{~m} \mathrm{a}^{-1}$ for EDML (Wesche et al., 2007) and $6 \mathrm{~m} \mathrm{a}^{-1}$ for NEEM (C. Hvidberg, personal communication, 2016). The divide flow at EDML is significantly more divergent compared to NEEM (Weikusat et al., 2017b). This flow results in a stronger and clearer c-axis CPO, giving a vertical girdle in pole figures in the central part of the core, while in NEEM the c-axis CPO resembles an elongated single maximum (Montagnat et al., 2014). In order to compare similar flow conditions, the sampled depths for this study were selected to reflect the deformation regime expected at ice divides, that is, extension normal to the dividing ridge and almost no deformation along the ridge and with vertical compression (triaxial deformation state). The c-axis CPO was not strongly developed and was similar for the depths selected: the eigenvalues of the second-order orientation tensor, which is typically used in glaciology, are $e_{1}=0.55$, $e_{2}=0.29$, and $e_{3}=0.16$ for NEEM at $718.2 \mathrm{~m}$ of depth and $e_{1}=0.46, e_{2}=0.36$, and $e_{3}=0.18$ for EDML at $655.5 \mathrm{~m}$ of depth (Eichler et al., 2013; Montagnat et al., 2014; Weikusat et al., 2013, 2017b).

Samples were transported at $-25^{\circ} \mathrm{C}$ from Antarctica to Bremerhaven, and from Greenland to Bremerhaven via Copenhagen, and subsequently stored at $-30^{\circ} \mathrm{C}$. Samples $(50 \times 100 \times 90 \mathrm{~mm})$ were cut parallel to the long axis of the drill core (Fig. 1b) using a bandsaw and polished in a $-25^{\circ} \mathrm{C}$ cold laboratory in Bremerhaven according to standard procedures using a microtome (e.g. Pauer et al., 1999; Wang et al., 2002). LM microstructure mapping was performed at $-20^{\circ} \mathrm{C}$ at AWI to obtain an overview of the microstructure using a Leica DM LM (Kipfstuhl et al., 2006) for high spatial resolution images (1 pixel edge $3.3 \mu \mathrm{m}$ ) and a large area scan macroscope (Krischke et al., 2015a, b) with slightly lower spatial resolution ( 1 pixel edge $5 \mu \mathrm{m}$ ). The method was also applied on-site immediately after drilling (in 2003 for the EDML and in 2010 for the NEEM samples). This method allowed us to monitor any microstructural changes caused by pressure and temperature change during transportation and storage (Miyamoto et al., 2009; Weikusat et al., 2012) and to locate regions of interest for EBSD, particularly as the subgrain microstructures were heterogeneously distributed. The c-axes and CPO were measured in the depth ranges of the EBSD samples with an automated fabric analyser system of the Australian Russell-Head type (Peternell et al., 2010).

Typical SGB microstructures were identified in LM images and selected for cryo-EBSD analysis. Small specimen blocks $(\sim 8 \times 8 \times 5 \mathrm{~mm})$ were cut using a handsaw for EBSD studies. As SGBs in ice are mainly located close to GBs, triple junctions, or grain necks (Weikusat et al., 2009b), EBSD-mapped areas could be selected such that up to $\sim 15$ SGBs could be measured in each map and up 

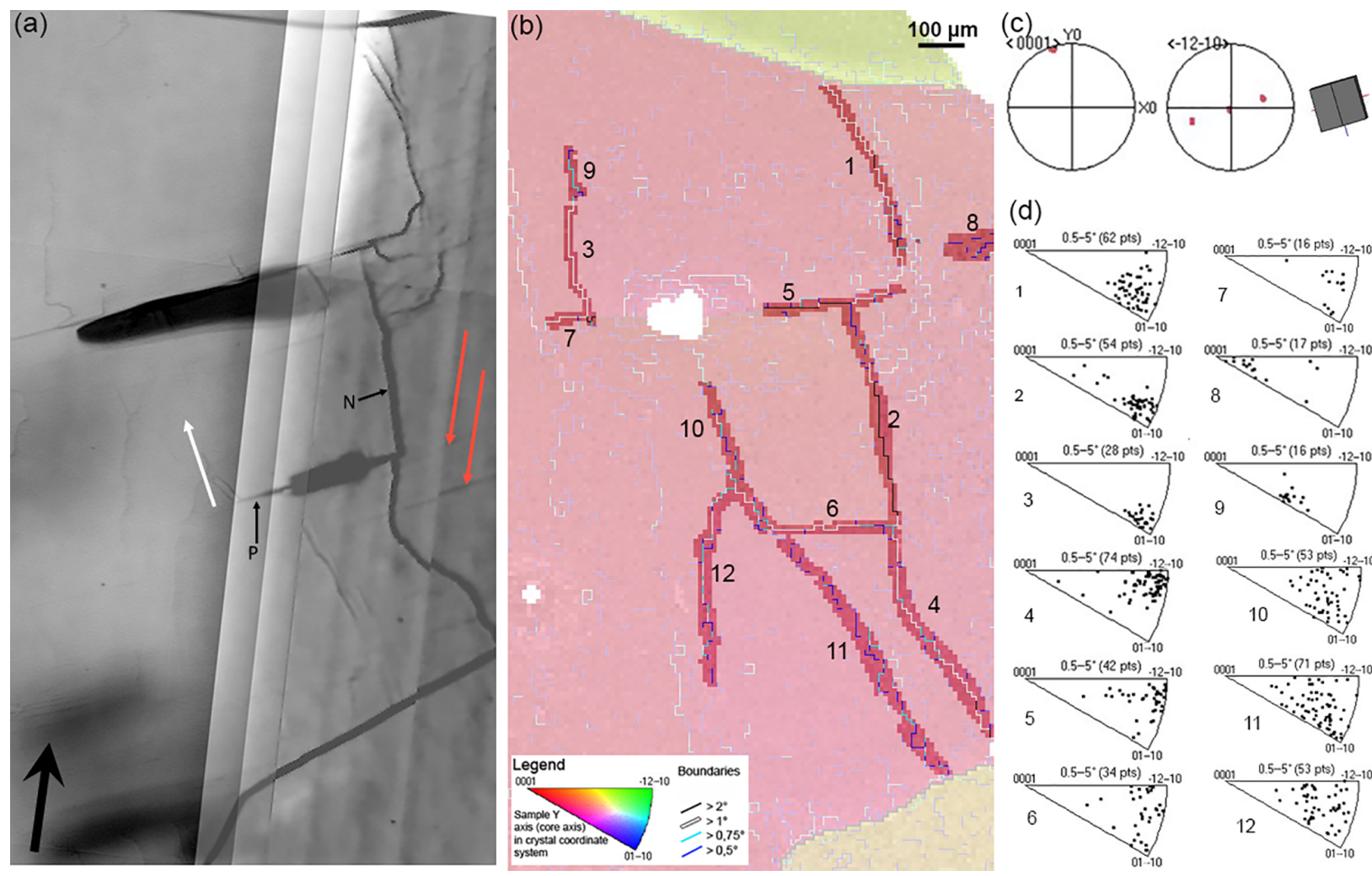

(d)

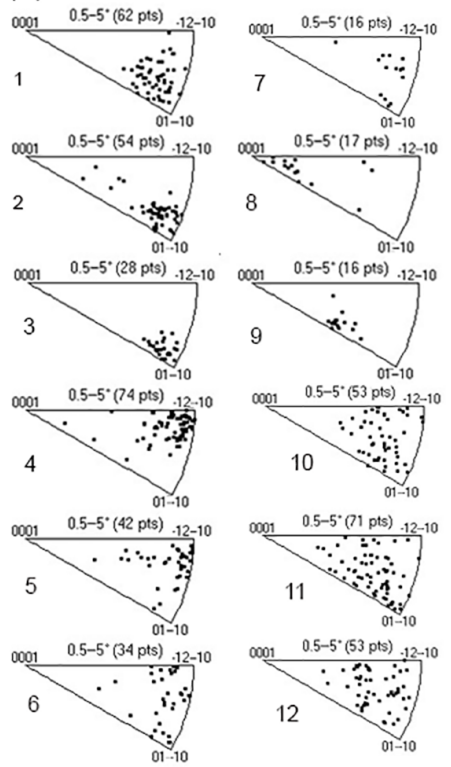

Figure 3. Microstructures used for the analysis of SGB types and slip systems: EDML sample (655.9 m of depth). (a) LM image of a map of sublimation-etched surface. The black arrow points to the top of the ice core. The white arrow indicates the orientation of the c-axis. A P-type boundary and an N-type boundary are labelled as examples. The red arrows show SGBs in LM that are not observed in the corresponding EBSD map. (b) EBSD map of the same area showing subsets of SGBs labelled 1-12. (c) Pole figure of the central grain in the EBSD map showing the c- and a-axes and a schematic of the crystal orientation. (d) Rotation axes of neighbouring pixels across the SGBs 1-12.

to 10 maps could cover almost the total area of the small block. The small blocks were again polished by microtoming and sublimation. A further high-resolution LM microstructure mapping step was performed. Polished specimens were stored in solid carbon dioxide (dry ice) at about $-70^{\circ} \mathrm{C}$ to reduce any further sublimation during transfer to Utrecht University (about 2 days to 3 weeks). A total of 4 samples were examined for the NEEM core and 10 for the EDML core.

Data were collected using an FEI Nova Nanolab 600 scanning electron microscope (SEM) equipped with an EBSD detector (Oxford Instruments, Abingdon, UK), a cryopreparation station, and a cryo-stage (Quorum Technologies Ltd, Ringmer, UK). Sample transfer to the SEM involved a further short sublimation step of a few minutes under vacuum (Weikusat et al., 2010). Typical measurement conditions for EBSD mapping were a working distance of $6-8 \mathrm{~mm},-123$ to $-150^{\circ} \mathrm{C}$ of sample stage temperature $\left(-145\right.$ to $-170^{\circ} \mathrm{C}$ of cold trap temperature), a $5 \times 10^{-5}$ to $3 \times 10^{-6} \mathrm{hPa}$ chamber pressure, 10 or $20 \mathrm{kV}$ of accelerating voltage, and an $8.4 \mathrm{nA}$ beam current. The sample surface was kept stable for 8-9 h under these conditions. Microstructures were imaged using secondary electrons. Channel 5 software (Oxford In- struments) was used to collect and analyse the EBSD data. The typical mapping rates was $0.15 \mathrm{~s} \mathrm{pixel}^{-1}$ with an indexing rate of $90 \%$. EBSD data processing was performed using standard noise reduction and orientation filtering as described by Weikusat et al. (2010). The angular resolution was about $0.5^{\circ}$ after orientation averaging. For EDML ( $656 \mathrm{~m}$ of depth) 4 individual samples were mapped with EBSD; for NEEM (719 m of depth) 10 individual samples were mapped.

Each individual SGB was imaged using LM and relocated in the SEM before EBSD mapping. The pixels across boundaries in an EBSD map were selected manually and saved as subsets of the map so that a narrow range of orientations from the boundary were analysed. This method avoided any orientation changes occurring away from the subgrain boundary. An upper misorientation angle of $5^{\circ}$ was taken for all SGBs (Weikusat et al., 2011). Neighbour pixel misorientation angles between 0.5 and $5^{\circ}$ were plotted in an inverse pole figure (IPF) for each subset to determine the rotation axes of the SGBs. The trace of the SGB was determined from the LM image and compared to the EBSD orientation information to avoid any artefacts caused by charging or poor sample alignment with respect to the tilt axis (Weikusat et al., 2010). 


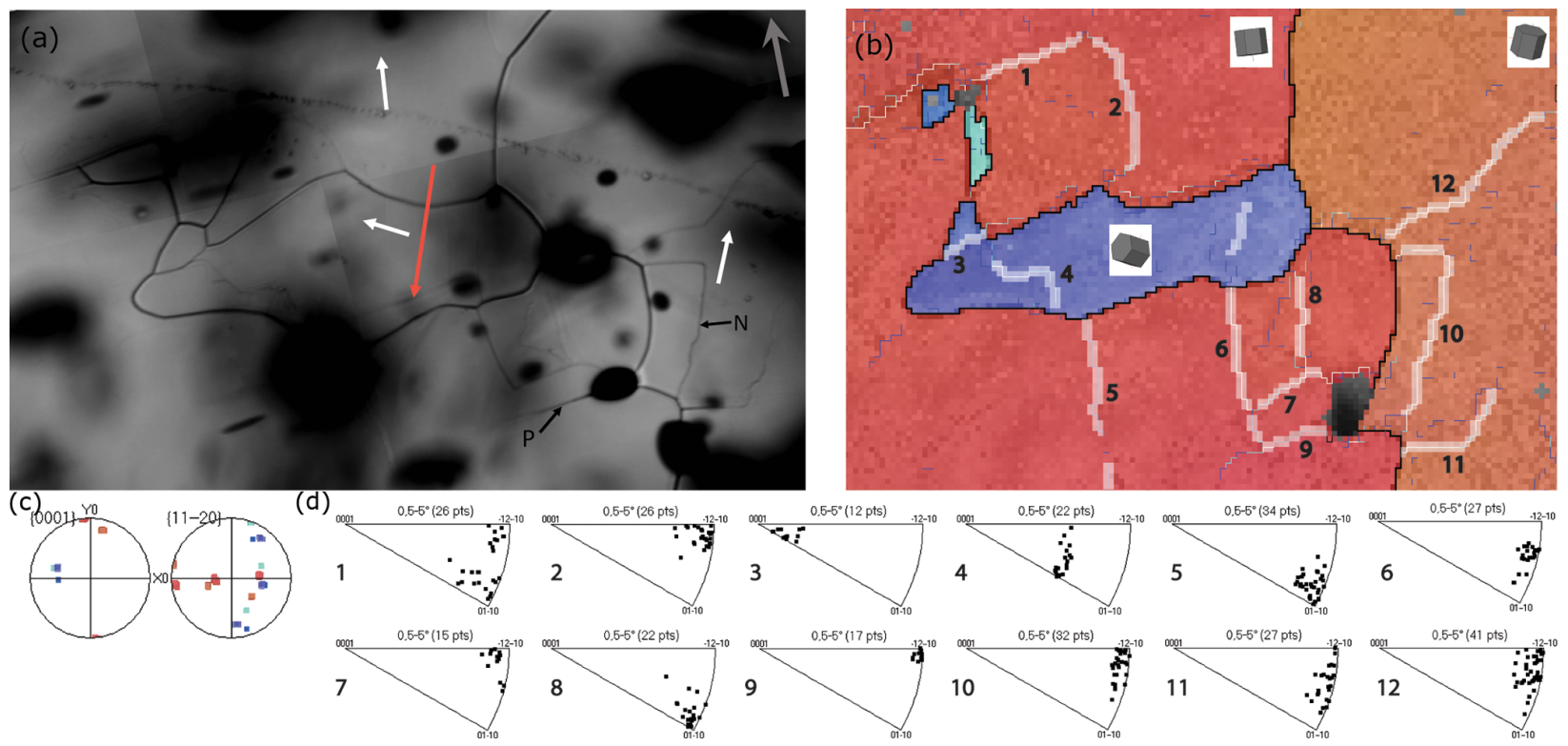

Figure 4. Microstructure analysis from NEEM sample. (a) LM microstructure map of sublimation-etched surface showing several GBs and SGBs. The vertical axis of the ice core is indicated by a dark grey arrow. The white arrows indicate the orientation of the c-axes. A P-type boundary and an N-type boundary are labelled as examples. The red arrow shows an SGB in LM that is not observed in the corresponding EBSD map. (b) Corresponding EBSD map showing SBG subsets labelled 1-12 and a schematic of the crystal orientation in the three grains shown. (c) Pole figure of the three grains shown in the EBSD map showing the c- and a-axes with the colour coding as in panel (b). (d) Rotation axes of the SGBs 1-12.

\section{Results}

The general appearance of the microstructures in the depth range of the two samples analysed in this study is shown in Fig. 2. Grains sizes range from a few millimetres to a few centimetres. Grain shapes are roughly equiaxed and interlocked and have curved boundaries. Several island grains are present. Changes in colour show lattice rotations within some grains.

\subsection{Subgrain boundary types}

Typical LM images for the EDML and NEEM samples are shown in Figs. 3a and 4a respectively. The stripy contrast in Fig. 3a (an artefact of automatic image processing) is aligned to the ice core axis, as in Fig. 1. Two SGB types are labelled in Fig. 3a: a P-type boundary with a trace parallel to the basal plane and an N-type boundary with a trace that is predominantly perpendicular to the basal plane.

\subsection{Misorientation angle range for subgrain boundaries using EBSD}

Approximately 230 individual SGBs were measured in the EDML samples and $\sim 180$ in the NEEM samples using EBSD. More SGBs (ca. 30\% for EDML and $20 \%$ for NEEM) were identified in LM images than in EBSD maps. The red arrows show three such boundaries in LM images (Figs. 3a and 4a) that were absent in the corresponding EBSD maps (Figs. 3b and $4 b$ ) of the same area. The boundaries are likely SGBs with misorientation angles that were below the angular detection limit of $\sim 0.5$ to $0.7^{\circ}$ found using our EBSD mapping conditions.

\subsection{Analysis of subgrain boundary types}

The same morphological SGB types (N-, P-, and Z-type and curved) identified in LM images were observed in EBSDmapped microstructures. The different SGB types were analysed using LM images and EBSD-mapped data (Figs. 3 and 4 ), and the trace of the boundary and the rotation axis, $\boldsymbol{R}$, were used to determine the slip systems.

\subsubsection{Subgrain boundary traces}

Small rotation differences were observed between many EBSD images and the LM images (see Fig. 3a and b). The orientations of the SGB traces were therefore made using the LM images combined with EBSD orientation data (Figs. 3c and $4 c)$.

\subsubsection{Subgrain boundary rotation axes}

Twelve SGB subsets used to determine rotation axes are highlighted in Fig. 3 for the EDML ice sample and in Fig. 4 for the NEEM ice core sample. The axes are displayed in inverse pole figures (Figs. $3 \mathrm{~d}$ and $4 \mathrm{~d}$ ). The rotation axes are 
spread over a large portion of the IPF. Nevertheless, some rotation axes cluster around certain poles.

The following types of rotation axes, $\boldsymbol{R}$, found in the two samples are summarized below.

1. $\boldsymbol{R}$ is in the basal plane (0001) with a general direction $\langle h k i 0\rangle$ (Fig. 3d, SGBs 1, 5, 6, 7 and Fig. 4d SGBs 6, 11, 12). Two special cases of this type of rotation axes occur, in which $R$ is either parallel to the prism plane normal, $\langle 01 \overline{1} 0\rangle$ (Fig. 3d, SGB 2, 3 and Fig. 4d, SGBs 5,8), or parallel to the a-axis $\langle 1 \overline{2} 10\rangle$ (Fig. 3d, SGB 4 and Fig. 4d, SGBs 2, 7, 9).

2. $\boldsymbol{R}$ is parallel to the c-axis, $\langle 0001\rangle$ (Fig. 3d, SGB 8 and Fig. 4d, SGB 3).

3. $\boldsymbol{R}$ is parallel to the pyramidal plane normal, $\langle h 0 \bar{i} l\rangle$ (Fig. 3d, SGB 9 and Fig. 4d, SGB 4).

4. $\boldsymbol{R}$ is not parallel to a specific orientation but dispersed (Fig. 3d, SGBs 10, 11, 12 and Fig. 4d, SGB 1).

\subsubsection{Combination of subgrain boundary traces and rotation axes}

In order to make a comparison with SGB statistics used in LM studies, we choose similar arrangements of the SGB plane with respect to the basal plane. These arrangements are shown in Fig. 5, which is an extended version of that given by Weikusat et al. $(2010,2011)$. A SGB boundary plane that is perpendicular to the basal plane (N-type) is shown in Fig. 5a and $b$, and a SGB plane that is parallel to the basal plane (P-type) is shown in Fig. 5c and d. For each of these arrangements, simple end member arrangements are chosen for the rotation axes (dots in Fig. 5e) with only one end member $\boldsymbol{R}$ lying in the basal plane (shaded in Fig. 5e). In Fig. 5a and d, $\boldsymbol{R}$ is in the basal plane (perpendicular to the c-axis), and in Fig. $5 b$ and c $\boldsymbol{R}$ is parallel to the c-axis. A shorthand notation is introduced to describe these four types of boundaries: $\mathrm{N}[a], \mathrm{N}[c], \mathrm{P}[c]$, and $\mathrm{P}[a]$ (Table 1$). \mathrm{N}[a]$ describes a SGB trace normal to the basal plane (N-type) with rotation axis in the basal plane (e.g. $\langle\boldsymbol{a}\rangle,\langle 01 \overline{1} 0\rangle$, or $\langle h k \bar{i} 0\rangle$ ); this is a tilt SGB (Fig. 5a). $\mathrm{N}[c]$ is also a tilt SGB of N-type but with a rotation axis parallel to the c-axis (Fig. $5 b$ ). $\mathrm{P}[c]$ has a SGB parallel to the basal plane (P-type) with rotation axis $[c]$ and is a twist type of boundary (Fig. 5c). $\mathrm{P}[a]$ is also a tilt boundary with the boundary parallel to the basal plane and a rotation axis in the basal plane (e.g. $\langle\boldsymbol{a}\rangle,\langle 01 \overline{1} 0\rangle$, or $\langle h k \bar{i} 0\rangle$ ). A compilation of the complete data set of combined information from rotation axes and SGB trace alignments is given in Table 2. The number frequency of SGBs is shown in terms of the rotation axes and the orientation of the SGB plane trace with respect to the basal plane trace.

The majority of SGBs could be allocated to certain classes with a well-defined trace orientation and rotation axis. The most common SGB types have $\boldsymbol{R}$ in the basal plane with
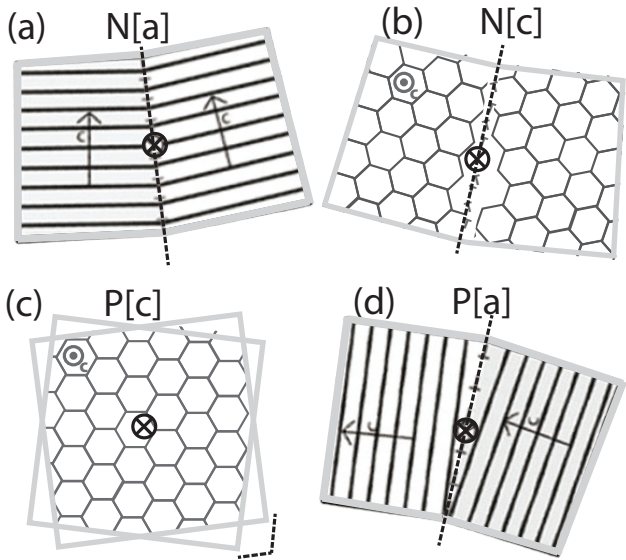

(e)

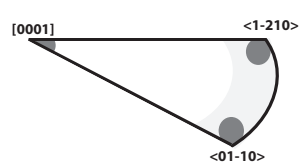

Figure 5. Schematic diagram showing some SGB types (modified from Weikusat et al., 2010, 2011). Four end member types of boundaries are shown. The rotation axes, $\boldsymbol{R}$, are marked as circles with an $\mathrm{X}$ inside; the parallel lines and hexagons represent the basal plane and are perpendicular to the c-axis, shown by arrows or as a grey circle with a dot inside. The dashed lines denote the SGB plane trace; in panel (c) the SGB plane is in the plane of the paper. Panels (a) and (b) show SGBs with the boundary plane perpendicular to the basal plane, which are N-type SGBs. Panels (c) and (d) show subgrain boundary planes parallel to the basal plane, which are Ptype SGBs. $\boldsymbol{R}$ is perpendicular to the c-axis in (a) and (d) and is parallel to the c-axis in (b) and (c). (e) A simplified inverse pole figure of the rotation axes parallel and perpendicular to the c-axis (dark grey circles). Possible slip systems for these SGB configurations are described in the text.

roughly equal proportions of $\mathrm{P}$ and $\mathrm{N}$ plane traces and $\boldsymbol{R}$ normal to the basal plane. SGBs of the $\mathrm{P}[a]$ type are shown in Fig. 3 for SGBs 5 and 7 and in Fig. 4 for SGBs 7, 9, and 11. SGBs of the $\mathrm{N}[a]$ type are shown in Fig. 3 for SGBs $1-4$ and in Fig. 4 for SGBs 2, 5, 6, 8, and 10. SGB 8 in Fig. 3 and SGB 3 in Fig. 4 are examples of a P-type SGB with a rotation axis $[0001](\mathrm{P}[c]$ type). SGBs with this rotation axis are rare in both ice cores, particularly the NEEM core (Table 2). SGB 3 in Fig. 4 is another example of a SGB with $\boldsymbol{R}=[0001]$ but combined with an N-type SGB trace $(\mathrm{N}[c])$. SGB 9 (Fig. 3) and the left half of SGB 4 (Fig. 4) are examples of a very rare N-type with $\boldsymbol{R}\langle h 0 \bar{i} l\rangle$. SGB 10 and 11 (Fig. 3) show N-type trace with $\boldsymbol{R}$ dispersed. There is a slightly higher fraction of dispersed axes in EDML compared to NEEM.

The EBSD data are grouped (Table 2, rightmost three columns) into simplified statistics in order to make a direct comparison between EBSD and X-ray Laue diffraction data published for the EDML ice core (Table 2 in Weikusat et 
Table 1. Summary and terminology of slip systems interpreted from analyses of LM and EBSD. $\boldsymbol{R}$ is the rotation axis of the subgrain boundary, and $\langle\boldsymbol{b}\rangle$ is the Burgers vector for slip. "Prim" is for primary and "sec" is for secondary. "Prism" stands for prismatic and "Pyr" stands for pyramidal.

\begin{tabular}{|c|c|c|c|c|c|c|c|c|}
\hline \multicolumn{3}{|c|}{ SGB geometry } & \multicolumn{2}{|c|}{ Slip system } & & \multirow{2}{*}{$\begin{array}{l}\text { Frequency } \\
\% \text { of all SGB }\end{array}$} & \multicolumn{2}{|c|}{ Examples } \\
\hline Name & Trace & Rotation axis $\langle\boldsymbol{R}\rangle$ & Slip plane & Burgers vector $\langle\boldsymbol{b}\rangle$ & Tilt/twist & & EDML (Fig. 3) & NEEM (Fig. 4) \\
\hline $\mathrm{N}[a]$ & N-type & $\langle\boldsymbol{a}\rangle$ or $\langle h k i 0\rangle$ & Basal & $\langle a\rangle$ & Tilt & $27-41$ & SGBs $1,2,3,4$ & SGBs $2,5,6,8,10$ \\
\hline $\mathrm{N}[c]$ & $\mathrm{N}$-type & {$[c]$} & Prism & $\langle a\rangle$ & Tilt & 1 & & SGB 3 \\
\hline $\mathrm{P}[c]$ & P-type & {$[c]$} & Basal & $\langle a\rangle$ & Twist & $1-3$ & SGB 8 & \\
\hline $\mathrm{P}[a]$ & P-type & $\langle a\rangle$ & Prim prism $\{1 \overline{1} 00\}$ & {$[\boldsymbol{c}]$ or $\langle\boldsymbol{c}+\boldsymbol{a}\rangle$} & Tilt & $5-7$ & & SGB 7, 9 \\
\hline $\mathrm{P}[a]$ & P-type & $\langle 1 \overline{1} 00\rangle$ & Sec prism $\{1 \overline{2} 10\}$ & {$[c]$ or $\langle\boldsymbol{c}+\boldsymbol{a}\rangle$} & Tilt & $6-10$ & & \\
\hline $\mathrm{P}[a]$ & P-type & $\langle\boldsymbol{a}\rangle$ or $\langle h k i 0\rangle$ & Prism / Pyr & $\langle c+a\rangle$ & Tilt & $29-37$ & SGB $5,6,7$ & SGB 1,11 \\
\hline
\end{tabular}

Table 2. Summary of the EBSD data statistics for EDML and NEEM samples. The columns show the SGB rotation axes, $\boldsymbol{R}$, and the rows show the alignment of the SGB traces with respect to the basal plane shown in Fig. $5 ; n$ is the number of SGBs, $\langle\boldsymbol{c}\rangle$ is $\langle 0001\rangle,\langle\boldsymbol{a}\rangle$ is $\langle 1 \overline{2} 10\rangle$, and ${ }^{*}$ signifies dispersed rotation axes. The outermost three columns give simplified statistics of the same data set for comparison with X-ray Laue diffraction (Weikusat et al., 2011).

\begin{tabular}{|c|c|c|c|c|c|c|c|c|c|c|}
\hline Rotation axis & & $\langle c\rangle$ & $\langle a\rangle$ & $\langle 01 \overline{1} 0\rangle$ & $\langle h k i 0\rangle$ & $\langle h 0 \bar{i} l\rangle$ & $* \|$ & $\langle c\rangle$ & in basal plane & $*$ \\
\hline \multirow{8}{*}{ 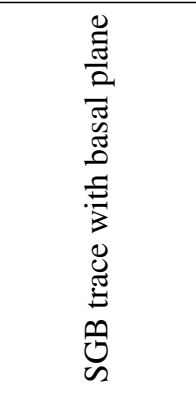 } & \multicolumn{10}{|c|}{ EDML (total $n_{>0.5^{\circ}}=227$ ) } \\
\hline & N-type & 3 & 11 & 21 & 30 & 2 & 16 & $3_{\mathrm{N}}[c]$ & $62_{\mathrm{N}[a]}$ & 18 \\
\hline & P-type & 7 & ${ }^{12} \mathrm{P}[a]$ prim & ${ }^{14} \mathrm{P}[a] \mathrm{sec}$ & 40 & 2 & 16 & ${ }^{7} \mathrm{P}[c]$ & ${ }^{66} \mathrm{P}[a]$ & 18 \\
\hline & Other & 7 & 10 & 5 & 15 & 0 & 16 & 7 & 30 & 16 \\
\hline & \multicolumn{10}{|c|}{ NEEM (total $\left.n_{>0.5^{\circ}}=181\right)$} \\
\hline & $\mathrm{N}$-type & 2 & 20 & 23 & 33 & 0 & 13 & $2 \mathrm{~N}[c]$ & $76_{\mathrm{N}[a]}$ & 13 \\
\hline & P-type & 2 & ${ }^{13} \mathrm{P}[a]$ prim & ${ }^{19} \mathrm{P}[a] \mathrm{sec}$ & 36 & 0 & 5 & $2 \mathrm{P}[c]$ & $68 \mathrm{P}[a]$ & 5 \\
\hline & Other & 0 & 1 & 3 & 3 & 0 & 8 & 0 & 7 & 8 \\
\hline
\end{tabular}

al., 2011). Table 2 confirms the conclusion of the X-ray Laue study, which showed a dominance of SGB with a rotation axis in the basal plane.

\section{Discussion}

\subsection{CPO and dislocation creep}

The microstructure and CPO (Fig. 2) suggest dislocation creep as the main deformation process with widespread formation of substructures. The CPOs in polar ice in general are consistent with the glide of basal dislocations as the main mechanism accommodating deformation (Schulson and Duval, 2009; Faria et al., 2014a, b, references therein). Our results confirm that subgrain boundaries are very common in ice, and the majority of all grains in all depths contain subgrains (Weikusat et al., 2009b), which reflects the high temperature deformation ( $>0.8 T_{\mathrm{m}}$, with $T_{\mathrm{m}}$ being the melting point temperature) of natural ice.

\subsection{Subgrain boundaries controlled by and geometrically related to host grain crystallography}

Those SGBs with clustered rotation axes are described in terms of the host crystallography. The spread in orientation of these axes is consistent with errors expected from low-angle misorientation boundaries (Prior et al., 1999). Our study provides statistics for around 400 SGBs in Antarctic and Greenland ice. Analyses of LM and EBSD microstructures are described in the following paragraphs in terms of the possible slip involved in forming the observed SGB types. By means of the geometrical relation with the host crystal, the SGB types are interpreted in terms of possible active dislocation slip systems. We use the term basal slip to describe dislocation glide on the basal plane and non-basal slip to describe dislocation glide on other glide planes.

$N$-type tilt boundaries with rotation axis in the basal plane: $N[a]$. A subgrain boundary normal to the basal plane (N- or Z-type) and a rotation axis, $\boldsymbol{R}$, in the basal plane with $\boldsymbol{R}=\langle h k i 0\rangle$ can be produced by an array of edge dislocations with $\boldsymbol{b}=\langle\boldsymbol{a}\rangle$ gliding in the basal plane, where $\boldsymbol{b}$ is the Burgers vector of the dislocation (Fig. 5a). The observed Ntype boundaries often have a general rotation axis orienta- 
tion $\langle h k i 0\rangle$ or are sub-parallel to $\langle 01 \overline{1} 0\rangle$ or $\langle 1 \overline{2} 10\rangle$, which can be explained by the glide and recovery of dislocations with the Burgers vectors $[\boldsymbol{a} 1]$ and $[\boldsymbol{a} 2]$. The vast majority of all N-type SGBs (around 85 to $75 \%$ ) have rotation axes in the basal plane and are thus potentially tilt boundaries made up of $\boldsymbol{b}=\langle\boldsymbol{a}\rangle$ edge dislocations that can glide on the basal plane (Table 2); that is, many $\mathrm{N}[a]$ boundaries are likely to be formed by the polygonization of dislocations produced by basal slip.

If an $\mathrm{N}[a]$ boundary is a twist boundary or has a significant twist component in the misorientation, then non-basal dislocations should be present along the boundary (see interactive discussion). $\mathrm{N}[a]$ twist boundaries could possibly be made with (i) one set of $\boldsymbol{b}=\langle\boldsymbol{a}\rangle$ dislocations and a second set of $\boldsymbol{b}=[\boldsymbol{c}]$ dislocations or (ii) with two sets of $\boldsymbol{b}=\langle\boldsymbol{a}+\boldsymbol{c}\rangle$ dislocations. In the case of the $\mathrm{N}[a]$ boundaries, it is not possible with 2-D EBSD data to determine whether the boundaries are pure tilt boundaries or if they have a twist component. Displaying the rotation axes and SGB normal in pole figures (in the sample reference frame) can be used to identify tilt and twist boundaries; however, in 2-D EBSD the dip of the SGB plane is not known. As N-type boundaries are commonly observed to be perpendicular to basal slip bands in transmitted light images (Weikusat et al., 2009b) and as basal slip is expected to be the dominant activated slip system (Hondoh, 2000, 2010; Piazolo et al., 2008), we expect that the $\mathrm{N}[a]$ SGBs will be dominantly produced by basal slip.

$N$-type tilt boundaries with rotation axis parallel to $c$ axis: $N[c]$. A subgrain boundary with a plane normal to the basal plane and with $\boldsymbol{R}=$ [0001] can be produced by an array of $\boldsymbol{b}=\langle\boldsymbol{a}\rangle$ edge dislocations slipping on a prismatic glide plane, such as $\{10 \overline{1} 0\}$ or $\{1 \overline{2} 10\}$. Like the N[a] type SGB, these dislocations have Burgers vectors in the basal plane, but unlike the $\mathrm{N}[a]$ type $\mathrm{SGB}$, the $\mathrm{N}[c]$ glides on non-basal planes (Fig. $5 b$ ); that is, $\mathrm{N}[c]$ boundaries involve non-basal slip. $\mathrm{N}[c]$ SGBs were rarely observed and made up only a small percent of the N-type SGBs (Table 2).

P-type twist boundaries: $P[c]$. A subgrain boundary accumulating dislocations parallel to the basal plane (P-type) and a resulting rotation around the c-axis [0001] can be produced by two or three sets of basal screw dislocations (Fig. 5c) with Burgers vectors $\boldsymbol{b}=\langle\boldsymbol{a}\rangle$ (Hondoh, 2000). Basal twist boundaries represent a minority ( $\sim 2$ to $8 \%$ ) of all parallel SGBs (Table 2).

P-type tilt boundaries: $P[a]$. A subgrain boundary parallel to the basal plane (P-type) and a rotation axis in the basal plane $(\langle\overline{1} 2 \overline{1} 0\rangle$ or $\langle 01 \overline{1} 0\rangle)$ can be produced by an array of nonbasal edge dislocations with $\boldsymbol{b}=[\boldsymbol{c}]$ or $\boldsymbol{b}=\langle\boldsymbol{c}+\boldsymbol{a}\rangle$ (Fig. 5d). An array of $\boldsymbol{b}=[\boldsymbol{c}]$ edge dislocations with $\{1 \overline{1} 00\}$ glide plane has a rotation axis $\boldsymbol{R}=\langle 1 \overline{2} 10\rangle$, while an array of $\boldsymbol{b}=[\boldsymbol{c}]$ edge dislocations with $\{1 \overline{2} 10\}$ glide plane has $\boldsymbol{R}=\langle 10 \overline{10}\rangle$. Many boundaries have a general rotation axis $\langle h k i 0\rangle$, suggesting that the glide planes of the $\boldsymbol{b}=[\boldsymbol{c}]$ dislocations can occur on a range of $\{h k i 0\}$ prismatic planes. Dislocation arrays of $\boldsymbol{b}=\langle\boldsymbol{c}+\boldsymbol{a}\rangle$ with two Burgers vectors, $\boldsymbol{b} 1=\boldsymbol{c}+\boldsymbol{a} 1$ and $\boldsymbol{b} 2=\boldsymbol{c}+\boldsymbol{a} 2$, could also produce this type of SGB. The $\langle\boldsymbol{c}+\boldsymbol{a}\rangle$ dislocations may glide on prism or pyramidal planes. Most of the P-type boundaries ( 72 to $90 \%$ ) are tilt boundaries with non-basal dislocations (Table 2).

A main result of our study is that a very high fraction of SGBs $(\mathrm{N}[c]$ \& $\mathrm{P}[a])$ in polar ice (ca. $30-40 \%$ of all SGBs) can be inferred to consist of non-basal dislocations and could therefore be formed by non-basal slip. Although somewhat unexpected with respect to the macroscopic behaviour of ice, this result is in accordance with earlier Xray work on a limited number of measurements in polar ice (Weikusat et al., 2011). This is in agreement with the recent findings of Chauve et al. (2017) who find up to $35 \%$ nonbasal slip in experimentally deformed artificial ice. The activation of non-basal slip suggests that, locally within grains, stresses were high enough to activate the harder slip systems. In common with many materials, natural ice often has a weakly developed core and mantle substructure (Gifkins, 1976; Faria et al., 2014b) with more SGBs occurring near the grain boundaries. The development of non-basal SGBs in the grain mantle is consistent with the stress concentration near grain boundaries and triple points, as has been found for hexagonal metals (Ion et al., 1982; Drury et al., 1985). In magnesium, non-basal slip only occurs in the grain mantles at temperatures less than $T<0.6 T_{\mathrm{m}}$ (Ion et al., 1982), while at higher temperatures non-basal slip is activated throughout the grains (Ion et al., 1982; Drury et al., 1985).

\subsection{Implications for the origin of non-basal dislocations from extended dislocations}

For the ice core samples from EDML and NEEM, the common $\mathrm{N}[a]$ type SGBs (Table 2) are made of basal dislocations (basal $\langle\boldsymbol{a}\rangle$ slip), while the equally common $\mathrm{P}[a]$ boundaries consist of non-basal $\boldsymbol{b}=[\boldsymbol{c}]$ or $\langle\boldsymbol{c}+\boldsymbol{a}\rangle$ dislocations (prism $[\boldsymbol{c}]$ slip).

Hondoh $(2000,2010)$ proposed that $\mathrm{P}[a]$ boundaries could be formed by the local slip of $\langle\boldsymbol{c}+\boldsymbol{a}\rangle$ screw dislocations in grains that were shortened parallel to the c-axis. According to Hondoh (2010) the strain produced by non-basal slip is rather limited and in the case of $\langle\boldsymbol{c}+\boldsymbol{a}\rangle$ pyramidal slip (Muguruma et al., 1966), limited strain can result in the formation of a P-type tilt wall made up of immobile $[\boldsymbol{c}]$ dislocations. In contrast, only a small proportion of the dislocations involved in basal slip are likely to become organized into dislocation walls. Analogous to the explanation by Hondoh (2010) we propose that the local slip of the $\langle\boldsymbol{c}+\boldsymbol{a}\rangle$ screws formed an immobile edge dislocation dipole (Fig. 6a). The dipole dislocations can dissociate into two dislocations; one with $\boldsymbol{b}=\langle\boldsymbol{a}\rangle$ glides away, leaving behind a $\boldsymbol{b}=[\boldsymbol{c}]$ dislocation (Fig. 6b). By repeating this process, an array of $\boldsymbol{b}=[\boldsymbol{c}]$ dislocations in the basal plane is formed (Fig. 6c). Shortening parallel to the $\mathrm{c}$-axis can be accommodated by local non-basal slip and by climb of the $\boldsymbol{b}=[\boldsymbol{c}]$ dislocations. 
(a)

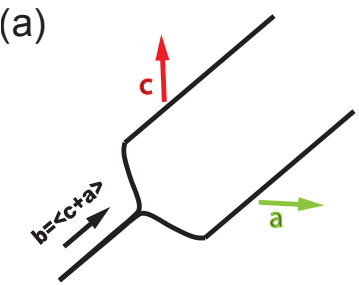

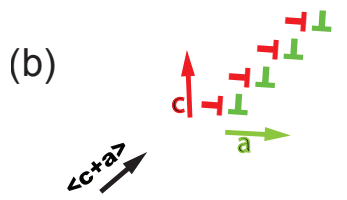

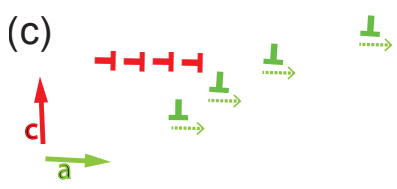

Figure 6. Schematic drawing of the dissociation of screw dislocation $\boldsymbol{b}=\langle\boldsymbol{c}+\boldsymbol{a}\rangle$ as one possibility to form a $\mathrm{P}[a]$ subgrain boundary; (a) $\langle\boldsymbol{c}+\boldsymbol{a}\rangle$ screw dislocation extending into an edge dislocation dipole (after Hondoh, 2006). (b) Dissociation into $\boldsymbol{b}=[\boldsymbol{c}]$ and $\langle\boldsymbol{a}\rangle$ dislocations; (c) $\boldsymbol{b}=\langle\boldsymbol{a}\rangle$ dislocations glide away, and $\boldsymbol{b}=[\boldsymbol{c}]$ dislocations are left behind to form a P-type SGB.

The other type of SGB that indicates non-basal slip activity is the $\mathrm{N}[c]$ type (prism $\langle\boldsymbol{a}\rangle$ slip), which occurs but is uncommon in the ice core samples (Table 2). Hondoh (2000, 2010) suggested that the $\boldsymbol{b}=\langle\boldsymbol{a}\rangle$ dislocations gliding on the prismatic planes could also move on to the basal plane, producing very irregular slip planes. The geometry of slip lines produced by prism $\langle\boldsymbol{a}\rangle$ slip on single crystals is similar to the Ztype SGBs (Weikusat et al. 2009b); thus some Z-boundaries may be non-basal slip bands rather than subgrains. This activation of non-basal slip has been directly observed in ice single crystals using X-ray topography (Higashi, 1988). Stress concentrations produced at grain boundaries or free crystal surfaces can result in the activation of non-basal dislocations (Wei and Dempsey, 1994; Shearwood and Whitworth, 1991; Levi et al., 1965). These studies show that strain accommodated by non-basal slip is limited, as the non-basal dislocations only glide on small portions of the slip plane, leaving behind a high density of immobile dislocations. As deformation in ice sheets occurs at very low stress and slow strain rates, the occurrence of recovery could make non-basal slip easier (Faria et al., 2014b), although it should be noted that non-basal slip systems have a higher stress exponent than basal slip, so the strength difference between the slip systems will increase with decreasing stress.

Many studies assume that all subgrains form by polygonization of geometrically necessary dislocations (Ashby, 1970; Ashby and Duval, 1985). However, in situ deforma- tion experiments on rock analogues (Means and Ree, 1988) and observations in some rock-forming minerals (Drury and Pennock, 2007) have shown that subgrains may originate in several ways. Means and Ree (1988) recognized seven types (I to VII) of subgrain boundaries in octachloropropane (OCP) deformed at 0.7 to $0.8 T_{\mathrm{m}}$. Two of these seven types are controlled by the host grain crystallography as they form from classical polygonization (I) and from glide polygonization (II). The SGB types discussed above (N $[a], \mathrm{N}[c], \mathrm{P}[c]$, $\mathrm{P}[a])$ are all related to the host grain crystallography and can thus be considered as Means and Ree type I or II. The crystallography of Means and Ree type I SGBs is determined by the geometrically necessary dislocations that accommodated the lattice bending in the grain leading to polygonization. Means and Ree (1988) suggested that their type II SGBs formed by glide polygonization and thus also reflect the active slip systems in the grain. This process is similar to kinking, which has been observed in ice on the crystal scale in experimentally deformed samples (Wilson et al., 1986), but also on the polycrystal scale (Jansen et al., 2016) in depth regimes below those of our samples where the CPO is very strong. Type II, however, will experience some modification of the SGB crystallography, as these are mobile tilt boundaries and a boundary migrating through a bent lattice will collect all types of dislocations. This could explain parts of the dispersion of the rotation axes observed (Figs. 3d, 4d). Means and Ree (1988) found that two-thirds of the SBGs in their OCP experiment were type I and II boundaries related to the crystallography of the lattice and thus influenced by the active slip systems. We also infer that about two-thirds of SGBs are crystallographically controlled; the remaining one-third of SGBs do not have a relationship to the crystallography of the host grain.

\subsection{Subgrain boundaries without connection to host grain crystallography}

The geometry of approximately $20-30 \%$ of all measured SGBs cannot be related to the host crystal orientation, so either the SGB trace cannot be determined because it is curved or at an arbitrary angle to the basal plane, or the rotation axis of the misorientation is dispersed (Table 2). These SGBs could be formed by processes similar to those described by Means and Ree for types III to VII, which are misorientation reduction by grain rotation or coalescence (III, IV), misorientation geometry resulting from combining two boundaries by impingement $(\mathrm{V})$, misorientation grown from an existing boundary (VI), and statistically evolving boundaries from optically strain-free grains (VII).

The crystallography of type III and IV SGBs should have no simple relationship to the active slip systems because these low-angle boundaries are formed by reduction of the misorientation angle between grain boundaries (III) or by coalescence of migrating grain boundaries (IV). A particular rotation axis is not expected for these boundaries, although 
the occurrence of a strong CPO will tend to produce preferred rotation axes (Mainprice et al., 1993). At deeper depth levels in polar ice, where a characteristically strong CPO development with ice sheet depth is generally observed (Weikusat et al., 2017b; Jansen et al., 2016; Montagnat et al., 2014; Fitzpatrick et al., 2014; Faria et al., 2014a, and references therein), we suggest that type III SGBs might occur. SGBs that develop from GBs may be recognizable as such because they are part of the grain boundary network. In order to evaluate this, other methods, such as the statistical evaluation of grain boundary networks (Binder et al., 2013b), are needed as larger grain populations have to be taken into account. However, in the sample studied here and for most other deep ice microstructures (Faria et al., 2014a), the vast majority of SGBs are microstructures that occur inside grains and are not low-angle SGBs that form part of a GB network. Type IV SGBs originating from grain coalescence might also be created by the mechanism of grain dissection (Steinbach et al., 2017).

The Means and Ree type V SGB involves the impingement of two migrating SGBs that develop a combined misorientation angle that is the sum of the two SGBs. If the boundaries are formed by the same slip system, then only the angle will be changed. Impingement of boundaries formed by different slip systems will produce a new misorientation that combines the dislocation content of the two boundaries. Such SGBs can be described as mixed boundaries composed of a mix of dislocations. A possible candidate for a SGB involving the impingement of two migrating SGBs might be SGB 1 in Fig. 4, which shows two separate orientation clusters of rotation axes.

The type VI SGBs increase in length and grow behind a migrating grain boundary, so their length does not reflect slip system activity; however, such boundaries would grow from boundaries initially produced by dislocation glide deformation, so the boundary misorientations should be related to the active slip systems. Given the extensive grain boundary migration that occurs at all levels in ice cores (Montagnat and Duval, 2004; Weikusat et al., 2009a), it is likely that many SGBs may have been extended by growth behind migrating boundaries. This is conceivable in particular with the common observation that only a part of SGBs crosses grains completely, while many others fade out towards the centre of a grain (Weikusat et al., 2009b; Hamann et al., 2007), such as SGB 9 in Fig. 3 and SGB 11 in Fig. 4. As Means and Ree type VI originates from mobile grain boundaries, this process may produce SGBs showing curved shapes, as observed for many SGBs in the trace class "other" (Table 2; SGBs 4 and 12 in Fig. 3). There is a tendency for some SGBs to be more deeply etched near grain boundaries (Weikusat et al., 2009b, 2011; Faria et al., 2014b), and SGBs appear to pin the migrating grain boundaries; for example, SGB 9 in Fig. 4. This type of SGB occurs in experimentally deformed ice (Hamann et al., 2007) that has undergone significant grain growth during deformation. These microstructures suggest that the P- and N-type boundaries in ice could be partly extended by growth behind migrating boundaries, such as the Means and Ree type VI SGB.

\subsection{Implications of SGB type and creep rate control}

Recent numerical simulations of ice deformation (Llorens et al., 2016; Llorens Verde et al., 2016; Steinbach et al., 2016, 2017; Richeton et al., 2017) employ full-field modelling approaches taking into account the anisotropic crystal plasticity of ice. Our evidence for the activation of non-basal slip systems in natural ice deformed at low stress supports the approach used in the full-field modelling. Llorens et al. (2016) and Llorens Verde et al. (2016) investigated the development of microstructure, subgrain formation, and slip system activity during pure and simple shear deformation. In the simulations, non-basal slip was 20 times harder than basal slip. The simulations showed that in pure shear, the activity of non-basal slip increased with strain related to the development of a strong CPO, which made basal slip more difficult. Even at low strains, $20 \%$ of the slip activity was accommodated by non-basal slip in the simulations. The microstructures produced in the simulations show heterogeneous activity of basal and non-basal slip systems, with different slip activity in different parts of grains resulting in the formation of SGBs with a non-basal dislocation content (Llorens et al., 2017). The simulations show that a significant fraction of non-basal subgrains can be formed with a relatively low level of activity in the harder non-basal slip systems.

The microstructures, subgrain development, and CPOs indicate that dislocation creep is an important mechanism in polar ice sheets. Most of the strain produced by dislocation creep should occur by glide on the easy basal $\langle\boldsymbol{a}\rangle$ slip system; however, basal slip only provides two of the four independent slip systems needed to accommodate heterogeneous deformation in hexagonal systems (Hutchinson, 1977), so either harder non-basal slip systems or other deformation mechanisms must be activated. These accommodating deformation mechanisms are likely to be the slowest processes, so they will usually be the rate-controlling processes for deformation. Suggested accommodating deformation processes are dislocation climb of basal $\langle\boldsymbol{a}\rangle$ dislocations, crossslip or climb of non-basal dislocations, and grain-boundarysensitive mechanisms, such as grain boundary sliding or diffusion. Grain-size-sensitive mechanisms, particularly grain boundary sliding, have been observed for fine-grained artificial ice (Goldsby and Kohlstedt, 1997, 2001) but are controversial for natural ice (Duval and Montagnat, 2002; Goldsby and Kohlstedt, 2002). The climb of dislocations gliding on the basal plane is a process related to recovery, which is rather active in ice, as ice on Earth is a hot material close to its pressure melting point (homologous temperature $T_{\text {hom }} \gg$ $0.7 T_{\mathrm{m}}$ ). Related to this, grain boundary migration, which in most cases is not a deformation mechanism, has been suggested to accommodate basal dislocation creep in ice via re- 
laxation of the internal stress concentrations at grain boundaries (Montagnat and Duval, 2000). For grain boundary sliding or grain boundary migration as rate-controlling accommodation processes, the activation of non-basal slip systems would not be expected. The evidence of non-basal dislocations being mobile in glide and climb or cross-slip to form subgrain boundaries in polar ice, as presented here, suggests the possibility that non-basal dislocation slip could be the rate-controlling deformation process in natural ice, at least in the Holocene-age samples investigated.

\section{Conclusions}

We presented an analysis of SGBs and the dislocation slip systems they indicate for 400 individual boundaries in Antarctic and Greenlandic deep ice cores (656 and $719 \mathrm{~m}$ of depth). Our study confirms the frequent occurrence of SGBs in natural ice.

Our analyses of the SGB traces with respect to the crystal orientation and the rotation axis associated with the boundary revealed (1) subgrain boundaries that can be related to slip system activity by their geometric relation to the host crystal orientations (ca. 70-80\%) and (2) subgrain boundaries that cannot be easily related to slip system activity (ca. 20-30\%).

The slip systems interpreted from our subgrain boundary measurements show that basal $\langle\boldsymbol{a}\rangle$ slip is the most common slip system indicated by the subgrain boundaries. However, there is an almost equal occurrence of subgrain boundaries indicating $\langle\boldsymbol{c}\rangle$ and/or $\langle\boldsymbol{c}+\boldsymbol{a}\rangle$ slip on non-basal planes. Far less frequent are subgrain boundaries indicating slip of $\langle\boldsymbol{a}\rangle$ screw dislocations on basal planes and slip of $\langle\boldsymbol{a}\rangle$ edge dislocations on prismatic planes.

Other possible means of producing subgrain boundaries in ice that cannot be easily related to slip system activity are discussed. SGBs originating from misorientation reduction in grain boundaries are likely to arise from the generally strong CPO that develops in deeper parts of EDML and NEEM natural ice. Subgrain boundary growth behind migrating grain boundaries is another possible SGB formation processes.

A main result of our study is that a very high fraction of SGBs in polar ice (ca. 30-40\% of all SGBs) consist of non-basal dislocations and could therefore be formed by nonbasal slip. We conclude from the relatively high frequency of SGBs consisting of non-basal dislocations that limited nonbasal slip was active at these depths in EDML and NEEM natural ice. This finding is consistent with current crystal plasticity descriptions for ice as employed in full-field modelling approaches, which assume the significant activation of non-basal slip systems. The occurrence of non-basal slip in natural samples implies that activation of the harder slip systems is involved in the low-stress deformation mechanisms of ice. Thus, available models which propose that basal slip is accommodated only by grain boundary processes, such as sliding or migration, need to be modified. Further work is needed to understand the exact role of non-basal slip and grain boundary processes in the low-stress deformation of ice, which is important for ice flow descriptions for different flow conditions of ice with respect to large-scale ice modelling and its constitutive ice flow description.

Data availability. Data are available at doi:10.1594/PANGAEA.879614 (Weikusat et al., 2017a).

Competing interests. The authors declare that they have no conflict of interest.

Special issue statement. This article is part of the special issue "Analysis of deformation microstructures and mechanisms on all scales". It is a result of the EGU General Assembly 2016, Vienna, Austria, 17-22 April 2016.

Acknowledgements. This project was funded by the German Science Foundation (DFG HA 5675/1-1 and WE 4695/1-2) within the SPP 1158 and the Helmholtz Association (VH-NG-802). The FIB-SEM microscope at Utrecht University is funded by NWO-groot and FEI. We thank two anonymous referees for their constructive reviews and Thomas Chauve for interactive commentary. NEEM is directed and organized by the Centre for Ice and Climate at the Niels Bohr Institute and the US NSF Office of Polar Programs. It is supported by funding agencies and institutions in Belgium (FNRS-CFB and FWO), Canada (NRCan/GSC), China (CAS), Denmark (FIST), France (IPEV, CNRS/INSU, CEA and ANR), Germany (AWI), Iceland (RannIs), Japan (NIPR), Korea (KOPRI), the Netherlands (NWO/ALW), Sweden (VR), Switzerland (SNF), the United Kingdom (NERC), and the USA (US NSF Office of Polar Programs). This work is a contribution to the European Project for Ice Coring in Antarctica (EPICA), a joint European Science Foundation and European Commission scientific programme funded by the EU and national contributions from Belgium, Denmark, France, Germany, Italy, the Netherlands, Norway, Sweden, Switzerland, and the United Kingdom. The main logistic support was provided by AWI (Dronning Maud Land).

The article processing charges for this open-access publication were covered by a Research Centre of the Helmholtz Association.

Edited by: Rüdiger Kilian

Reviewed by: two anonymous referees 


\section{References}

Alley, R., Gow, A., and Meese, D.: Mapping c-axis fabrics to study physical processes in ice, J. Glaciol., 41, 197-203, 1995.

Alley, R. B.: Flow-law hypotheses for ice-sheet modelling, J. Glaciol., 38, 245-256, 1992.

Alley, R. B., Clark, P. U., Huybrechts, P., and Joughin, I.: Ice-Sheet and Sea-Level Changes, Science, 310, 456-460, 2005.

Arnaud, L., M., G., Barnola, J. M., and Duval, P.: Imaging firn and bubly ice in coaxial reflected light: a new technique for the characterization of these porous media, J. Glaciol., 44, 326-332, 1998.

Ashby, M. F.: The deformation of plastically non-homogenous materials, Philos. Mag., 21, 399-424, 1970.

Ashby, M. F. and Duval, P.: The creep of polycrystalline ice, Cold Reg. Sci. Technol., 11, 285-300, 1985.

Baker, I.: Imaging dislocations in ice, Microsc. Res. Techn., 62, 7082, 2003.

Barnes, P. R. F.: Comment on "Grain boundary ridge on sintered bonds between ice crystals" [J. Appl. Phys. 90, 5782 (2001)], J. Appl. Phys., 93, 783-785, 2003.

Barrette, P. D. and Sinha, N. K.: Lattice misfit as revealed by dislocation etch pits in a deformed ice crystal, J. Mater. Sci. Lett., 13, 1478-1481, 1994.

Beem, L. H., Jezek, K. C., and Van Der Veen, C.: Basal melt rates beneath Whillans ice stream, west antarctica, J. Glaciol., 56, 647-654, 2010.

Binder, T., Garbe, C., Wagenbach, D., Freitag, J., and Kipfstuhl, S.: Extraction and parameterization of grain boundary networks, using a dedicated method of automatic image analysis, J. Microsc., 250, 130-141, 2013a.

Binder, T., Weikusat, I., Freitag, F., Garbe, C., Wagenbach, D., and Kipfstuhl, S.: Microstructure through an ice sheet, Materials Science Forum 753, 481-484, Trans Tech Publications, Switzerland, Proceedings of ReX\&GG2013, 5-10 May 2013, Sydney, 2013b.

Bindoff, N. L., Willebrand, J., Artale, V., Cazenave, A., Gregory, J., Gulev, S., Hanawa, K., Quere, C. K., Levitus, S., Nojiri, Y., Shum, C., Talley, L., and Unnikrishnan, A.: Climate Change 2007: The Physical Science Basis. Contribution of Working Group I to the Fourth Assessment Report of the Intergovernmental Panel on Climate Change, Cambridge University Press, Cambridge, UK and New York, NY, USA, chap. Observations, Oceanic Climate Change and Sea Level, 385-432, 2007.

Bons, P. D., Jansen, D., Mundel, F., Bauer, C. C., Binder, T., Eisen, O., Jessell, M. W., Llorens, M.-G., Steinbach, F., Steinhage, D., and Weikusat, I.: Converging flow and anisotropy cause largescale folding in Greenland's ice sheet, Nat. Commun., 7, 11427, https://doi.org/10.1038/ncomms11427, 2016.

Breton, D. J., Baker, I., and Cole, D. M.: Microstructural evolution of polycrystalline ice during confined creep testing, Cold Reg. Sci. Technol., 127, 25-36, 2016.

Bryant, G. W. and Mason, B. J.: Etch pits and dislocations in ice crystals, Phil. Mag., Structure and Properties of Condensed Matter, 5, 1221-1227, 1960.

Chauve, T., Montagnat, M., Piazolo, S. C., Journaux, B., Wheeler, J., Barou, F., Mainprice, D., and Tommasi, A.: Non-basal dislocations should be accounted for in simulating ice mass flow, Earth Planet. Sc. Lett., 473, 247-255, https://doi.org/10.1016/j.epsl.2017.06.020, 2017.
Dansgaard, W., Clausen, H. B., Gundestrup, N., Hammer, C. U., Johnsen, S. F., Kristinsdottir, P. M., and Reeh, N.: A New Greenland Deep Ice Core, Science, 218, 1273-1277, 1982.

Drury, M. and Pennock, G.: Subgrain Rotation Recrystallization in Minerals Materials, Sci. Forum, 550, 95-104, 2007.

Drury, M., Humphreys, F., and White, S.: Large strain deformation studies using polycrystalline magnesium as a rock analogue. Part II: dynamic recrystallisation mechanisms at high temperatures, Phys. Earth Planet. In., 40, 201-207, 1985.

Duval, P. and Montagnat, M.: Comment on "Superplastic deformation of ice: Experimental observations" by D. L. Goldsby and D. L. Kohlstedt, J. Geophys. Res.-Sol. Ea., 107, 2082, https://doi.org/10.1029/2001JB000946, 2002.

Duval, P., Ashby, M. F., and Anderman, I.: Rate-contolling processes in the creep of polycrystalline ice, J. Phys. Chem., 87, 4066-4074, 1983.

Eichler, J., Weikusat, I., and Kipfstuhl, S.: Orientationtensor eigenvalues along the NEEM ice core, https://doi.org/10.1594/PANGAEA.838059, 2013.

Eichler, J., Kleitz, I., Bayer-Giraldi, M., Jansen, D., Kipfstuhl, S., Shigeyama, W., Weikusat, C., and Weikusat, I.: Location and distribution of micro-inclusions in the EDML and NEEM ice cores using optical microscopy and in situ Raman spectroscopy, The Cryosphere, 11, 1075-1090, https://doi.org/10.5194/tc-11-10752017, 2017.

EPICA: Eight glacial cycles from an Antarctic ice core, Nature, 429, 623-628, 2004.

EPICA: One-to-one coupling of glacial climate variability in Greenland and Antarctica, Nature, 444, 195-198, 2006.

Faria, S. H., Weikusat, I., and Azuma, N.: The Microstructure of Polar Ice. Part I: Highlights from ice core research, J. Struct. Geol., 61, 2-20, 2014a.

Faria, S. H., Weikusat, I., and Azuma, N.: The microstructure of polar ice. part II: State of the art, Journal of Structural Geology, $61,21-49,2014 b$.

Fitzpatrick, J. J., Voight, D. E., Fegyveresi, J. M., Stevens, N. T., Spencer, M. K., Cole-Dai, J., Alley, R. B., Jardine, G. E., Cravens, E. D., Wilen, L. A., Fudge, T., and McConnell, J. R.: Physical properties of the WAIS Divide ice core, J. Glaciol., 60, 1181-1198, 2014.

Fukuda, A. and Higashi, A.: X-ray diffraction topographic studies of dislocations in natural large ice single crystals, Jpn. J. Appl. Phys., 8, 993-999, 1969.

Fukuda, A., Hondoh, T., and Higashi, A.: Dislocation mechansisms of plastic deformation of ice, J. Phys., 48, 163-171, 1987.

Gifkins, R. C.: Grain-boundary sliding and its accommodation during creep and superplasticity, Metall. Trans. A, 7, 1225-1232, 1976.

Glen, J. W.: The creep of polycrystalline ice, P. R. Soc. Lond. A, 228, 519-538, 1955.

Goldsby, D. and Kohlstedt, D.: Grain boundary sliding in finegrained ice, Scripta Mater., 37, 1399-1406, 1997.

Goldsby, D. L. and Kohlstedt, D. L.: Superplastic deformation of ice: experimental observations, J. Geophys. Res.-Sol. Ea., 106, 11017-11030, 2001.

Goldsby, D. L. and Kohlstedt, D. L.: Superplastic deformation of ice: experimental observations: reply, J. Geophys. Res.-Sol. Ea., 107, 2313, https://doi.org/10.1029/2002JB001842, 2002. 
Gottstein, G. and Shvindlerman, L. S.: Grain boundary migration in metals, CRC Press, Taylor \& Francis Group, Boca Raton, London, New York, 1999.

Greve, R. and Blatter, H.: Dynamics of Ice Sheets and Glaciers, edited by: Hutter, K., Springer-Verlag Berlin Heidelberg, 287 pp., 2009.

Hamann, I., Weikusat, C., Azuma, N., and Kipfstuhl, S.: Evolution of ice crystal microstructures during creep experiments, J. Glaciol., 53, 479-489, 2007.

Higashi, A., Fukuda, A., Shoji, H., Oguro, M., Hondoh, T., and Goto-Azuma, K.: Lattice defects in ice crystals, Hokkaido University Press, Sapporo, Japan, 1988.

Hirth, J. P. and Lothe, J.: Theory of Dislocations. Krieger Publishing Company, 857 pp., 1982.

Hock, R.: Glacier melt: a review of processes and their modelling, Prog. Phys. Geogr., 29, 362-391, 2005.

Hondoh, T.: Nature and behaviour of dislocations in ice, in: Physics of Ice Core Records, edited by: Hondoh, T., Hokkaido University Press, Sapporo, 3-24, 2000.

Hondoh, T.: Anisotropy of ice plasticity and dislocations in ice : anomalous properties of hexagonal ice Ih associated with cubic structure Ic Low temperature, Science, 64, 141-156, 2006.

Hondoh, T.: An overview of microphysical processes in ice sheets: Toward nanoglaciology, in: Physics of Ice Core Records II, edited by: Hondoh, T., Vol. 68, Supplement Issue of Low Temperature Science, 2010.

Hughes, T.: Modeling ice sheets from the bottom up, Quaternary Sci. Rev., 28, 1831-1849, 2009.

Humphreys, F.: Characterisation of fine-scale microstructures by electron backscatter diffraction (EBSD), Scr. Mater., 51, 771776, 2004.

Humphreys, F. J. and Hatherly, M.: Recrystallization and Related Annealing Phenomena, Elsevier, Oxford, UK, 574 pp., 2004.

Hutchinson, J. W.: Creep and plasticity of hexagonal polycrystals as related to single crystal slip, Metall. Mater. Trans. A, 8, 14651469, 1977.

Huybrechts, P.: Ice Sheet Modeling, chap. Encyclopedia of the Antarctic, Routledge, New York and London, 514-517, 2007.

Iliescu, D., Baker, I., and Chang, H.: Determining the Orientations of Ice Crystals Using Electron Backscatter Patterns, Microsc. Res. Techniq., 63, 183-187, 2004.

Ion, S., Humphreys, F., and White, S. H.: Dynamic recrystallisation and the development of microstructure during the high temperature deformation of magnesium, Acta Metall., 30, 1909-1919, 1982.

IPCC: Climate Change 2007: The Physical Science Basis. Contribution of Working Group I to the Fourth Assessment Report of the Intergovernmental Panel on Climate Change, chap. Summary for Policymakers, edited by: Solomon, S., Qin, D., Manning, M., Chen, Z., Marquis, M., Averyt, K. B., Tignor, M., and Miller, H. L., Cambridge University Press, Cambridge, UK and New York, NY, USA, 2007.

IPCC: Climate change 2014: Synthesis report. contribution of working groups I, II and III to the Fifth assessment report of the intergovernmental panel on climate change, Core Writing Team, edited by: Pachauri, R. K. and Meyer, L. A., IPCC, Geneva, Switzerland, 151, 2014.

Jansen, D., Llorens, M.-G., Westhoff, J., Steinbach, F., Kipfstuhl, S., Bons, P. D., Griera, A., and Weikusat, I.: Small-scale distur- bances in the stratigraphy of the NEEM ice core: observations and numerical model simulations, The Cryosphere, 10, 359-370, https://doi.org/10.5194/tc-10-359-2016, 2016.

Joughin, I., Smith, B., Howat, I., and Scambos, T.: MEaSUREs Greenland Ice Velocity Map from InSAR Data, Version 2. Boulder, Colorado, USA: NASA DAAC at the National Snow and Ice Data Center, https://doi.org/10.5067/OC7B04ZM9G6Q, 2015.

Ketcham, W. M. and Hobbs, P. V.: An experimental determination of the surface energies of ice, Philos. Mag., 19, 1161-1173, 1969.

Kipfstuhl, S., Hamann, I., Lambrecht, A., Freitag, J., Faria, S., Grigoriev, D., and Azuma, N.: Microstructure mapping: a new method for imaging deformation induced microstructural features of ice on the grain scale, J. Glaciol., 52, 398-406, 2006.

Kipfstuhl, S., Faria, S. H., Azuma, N., Freitag, J., Hamann, I., Kaufmann, P., Miller, H., Weiler, K., and Wilhelms, F.: Evidence of dynamic recrystallization in polar firn, J. Geophys. Res., 114, B05204, https://doi.org/10.1029/2008JB005583, 2009.

Krischke, A., Oechsner, U., and Kipfstuhl, S.: Microstructure Analysis of Polar Ice Cores Physics' Best, DPG, WILEY-VCH Verlag, Weinheim, 20-22, 2015a.

Krischke, A., Oechsner, U., and Kipfstuhl, S.: Rapid Microstructure Analysis of Polar Ice Cores Optik \& Photonik, WILEY-VCH Verlag, Weinheim, 10, 32-35, 2015 b.

Kuramoto, T., Goto-Azuma, K., Hirabayashi, M., Miyake, T., Motoyama, H., Dahl-Jensen, D., and Steffensen, J. P.: Seasonal variations of snow chemistry at NEEM, Greenland, Ann. Glaciol., 52, 193-200, 2011.

Lemke, P., Ren, J., Alley, R., Allison, I., Carrasco, J., Flato, G., Fujii, Y., Kaser, G., Mote, P., Thomas, R., and Zhang, T.: Climate Change 2007: The Physical Science Basis. Contribution of Working Group I to the Fourth Assessment Report of the Intergovernmental Panel on Climate Change, Cambridge University Press, Cambridge, UK and New York, NY, USA, 337-383, 2007.

Levi, L., DeAchaval, E. M., and Suraski, E.: Experimental study of non-basal dislocations in ice crystals, J. Glaciol., 5, 691-699, 1965.

Lloyd, G. E., Farmer, A. B., and Mainprice, D.: Misorientation analysis and the formation and orientation of subgrain and grain boundaries, Tectonophysics, 279, 55-78, 1997.

Llorens, M.-G., Griera, A., Bons, P. D., Lebensohn, R. A., Evans, L. A., Jansen, D., and Weikusat, I.: Full-field predictions of ice dynamic recrystallisation under simple shear conditions, Earth Planet. Sc. Lett., 450, 233-242, 2016.

Llorens, M.-G., Griera, A., Steinbach, F., Bons, P. D., Gomez-Rivas, E., Jansen, D., Roessiger, J., Lebensohn, R. A., and Weikusat, I.: Dynamic recrystallisation during deformation of polycrystalline ice: insights from numerical simulations, Philos. T. R. Soc. A, 375, 20150346, https://doi.org/10.1098/rsta.2015.0346, 2017.

Llorens Verde, M. G., Griera, A., Bons, P. D., Roessiger, J., Lebensohn, R., Evans, L., and Weikusat, I.: Dynamic recrystallisation of ice aggregates during co-axial viscoplastic deformation: a numerical approach, J. Glaciol., 62, 359-377, 2016.

Mainprice, D., Lloyd, G. E., and Casey, M.: Individual orientation measurements in quartz polycrystals - advantages and limitations for texture and petrophysical property determinations, J. Struct. Geol., 15, 1169-1187, 1993.

Means, W. D. and Ree, J. H.: Seven types of subgrain boundaries in OCP, J. Struct. Geol., 10, 765-770, 1988. 
Miyamoto, A., Saito, T., and Hondoh, T.: Visual observation of volume relaxation under different storage temperatures in the dome fuji ice core, Antarctica, in: Physics of Ice Core Records II, edited by: Hondoh, T., Vol. 2 of PICR, 68, 73-79, 2009.

Miyamoto, A., Weikusat, I., and Hondoh, T.: Complete determination of ice crystal orientation and microstructure investigation on ice core samples enabled by a new x-ray laue diffraction method, J. Glaciol., 57, 67-74, 2011.

Montagnat, M. and Duval, P.: Rate controlling processes in the creep of polar ice, influence of grain boundary migration associated with recrystallization, Earth Planet. Sc. Lett., 183, 179-186, 2000 .

Montagnat, M. and Duval, P.: Dislocations in ice and deformation mechanisms: from single crystals to polar ice, Defect and Diffusion Forum, Scitec Pub., 229, 43-54, 2004.

Montagnat, M., Duval, P., Bastie, P., Hamelin, B., Brissaud, O., de Angelis, M., Petit, J.-R., and Lipenkov, V. Y.: High crystalline quality of large single crystals of subglacial ice above lake vostok (antarctica) revealed by hard x-ray diffraction, Comptes Rendus de l'Academie des Sciences - Series IIA - Earth and Planetary Science, 333, 419-425, 2001.

Montagnat, M., Duval, P., Bastie, P., Hamelin, B., and Lipenkov, V. Y.: Lattice distortion in ice crystals from the Vostok core (Antarctica) revealed by hard X-ray diffraction, implication in the deformation of ice at low stresses, Earth Planet. Sc. Lett., 214, 369378, 2003.

Montagnat, M., Azuma, N., Dahl-Jensen, D., Eichler, J., Fujita, S., Gillet-Chaulet, F., Kipfstuhl, S., Samyn, D., Svensson, A., and Weikusat, I.: Fabric along the NEEM ice core, Greenland, and its comparison with GRIP and NGRIP ice cores, The Cryosphere, 8 , 1129-1138, https://doi.org/10.5194/tc-8-1129-2014, 2014.

Montagnat, M., Chauve, T., Barou, F., Tommasi, A., Beausir, B., and Fressengeas, C.: Analysis of dynamic recrystallization of ice from EBSD orientation mapping, Front. Earth Sci., 3, https://doi.org/10.3389/feart.2015.00081, 2015.

Muguruma, J., Mae, S., and Higashi, A.: Void formation by nonbasal glide in ice single crystals, Philos. Mag., 13, 625-629, 1966.

Mullins, W. W.: Theory of thermal grooving, J. Appl. Phys., 28, 333-339, 1957.

Nakaya, U.: Mechanical properties of single crystal of ice, Part I. Geometry of deformation, US Army Snow Ice and Permafrost Research Establishment, Research Report 28, 1958.

NEEM community members: Eemian interglacial reconstructed from a greenland folded ice cores, Nature, 493, 489-494, 2013.

Neumann, B.: Texture development of recrystallised quartz polycrystals unravelled by orientation and misorientation characteristics, J. Struct. Geol., 22, 1695-1711, 2000.

Nishida, K. and Narita, H.: Three-dimensional observations of ice crystal characteristics in polar ice sheets, J. Geophys. Res., 101, 21311-21317, 1996.

Obbard, R., Baker, I., and Sieg, K.: Using electron backscatter diffraction patterns to examine recrystallization in polar ice sheets, J. Glaciol., 52, 546-557, 2006.

Oerter, H., Drücker, C., Kipfstuhl, S., and Wilhelms, F.: Kohnen station - the drilling camp for the epica deep ice core in dronning maud land, Polarforschung, 78, 1-23, 2009.

Pauer, F., Kipfstuhl, S., Kuhs, W. F., and Shoji, H.: Air clathrate crystals from the GRIP deep ice core, Greenland: a number-
, size- and shape-distribution study, J. Glaciol., 45, 22-30, https://doi.org/10.1017/S0022143000003002, 1999.

Peternell, M., Russell-Head, D. S., and Wilson, C. J. L.: A technique for recording polycrystalline structure and orientation during in situ deformation cycles of rock analogues using an automated fabric analyser, J. Microsc., 242, 181-188, 2010.

Piazolo, S., Montagnat, M., and Blackford, J. R.: Sub-structure characterization of experimentally and naturally deformed ice using cryo-EBSD, J. Microsc., 230, 509-519, 2008.

Prior, D. J., Boyle, A. P., Brenker, F., Cheadle, M. C., Day, A., Lopez, G., Peruzzo, L., Potts, G. J., Reddy, S., Spiess, R., Timms, N. E., Trimby, P., Wheeler, J., and Zetterström, L.: The application of electron backscatter diffraction and orientation contrast imaging in the SEM, to textural problems in rocks, Am. Mineral., 84, 1741-1759, 1999.

Prior, D. J., Wheeler, J., Peruzzo, L., Spiess, R., and Storey, C.: Some garnet microstructures: an illustration of the potential of orientation maps and misorientation analysis in microstructural studies, J. Struct. Geol., 24, 999-1011, 2002.

Prior, D., Lilly, K., Seidemann, M., Vaughan, M., Becroft, L., Easingwood, R., Diebold, S., Obbard, R., Daghlian, C., Baker, I., Caswell, T., Golding, N., Goldsby, D., Durham, W. B., Piazolo, S., and Wilson, C.: Making EBSD on water ice routine, J. Microsc., 259, 237-256, 2015.

Randle, V. and Engler, O.: Introduction to texture analysis: Macrotexture, Microtexture and Orientation Mapping, CRC Press, Taylor \& Francis Group, Boca Raton, London, New York, 388 pp., 2000.

Rasmussen, S. O., Abbott, P. M., Blunier, T., Bourne, A. J., Brook, E., Buchardt, S. L., Buizert, C., Chappellaz, J., Clausen, H. B., Cook, E., Dahl-Jensen, D., Davies, S. M., Guillevic, M., Kipfstuhl, S., Laepple, T., Seierstad, I. K., Severinghaus, J. P., Steffensen, J. P., Stowasser, C., Svensson, A., Vallelonga, P., Vinther, B. M., Wilhelms, F., and Winstrup, M.: A first chronology for the North Greenland Eemian Ice Drilling (NEEM) ice core, Clim. Past, 9, 2713-2730, https://doi.org/10.5194/cp-92713-2013, 2013.

Richeton, T., Le, L., Chauve, T., Bernacki, M., Berbenni, S., and Montagnat, M.: Modelling the transport of geometrically necessary dislocations on slip systems: application to single- and multi-crystals of ice, Model. Simul. Mater. Sc., 25, 025010, https://doi.org/10.1088/1361-651X/aa5341, 2017.

Ruth, U., Barnola, J.-M., Beer, J., Bigler, M., Blunier, T., Castellano, E., Fischer, H., Fundel, F., Huybrechts, P., Kaufmann, P., Kipfstuhl, S., Lambrecht, A., Morganti, A., Oerter, H., Parrenin, F., Rybak, O., Severi, M., Udisti, R., Wilhelms, F., and Wolff, E.: "EDML1": a chronology for the EPICA deep ice core from Dronning Maud Land, Antarctica, over the last 150000 years, Clim. Past, 3, 475-484, https://doi.org/10.5194/cp-3-475-2007, 2007.

Saylor, D. M. and Rohrer, G. S.: Measuring the Influence of GrainBoundary Misorientation on Thermal Groove Geometry in Ceramic Polycrystals, J. Am. Ceram. Soc., 82, 1529-1536, 1999.

Schulson, E. M. and Duval, P.: Creep and Fracture of Ice, Cambridge University Press, Cambridge, UK, 2009.

Shearwood, C. and Whitworth, R. W.: The velocity of dislocations in ice, Philos. Mag. A, 64, 289-302, 1991. 
Song, M., Baker, I., and Cole, D. M.: The effect of particles on creep rate and microstructures of granular ice, J. Glaciol., 54, 533-537, 2008.

Steinbach, F., Bons, P. D., Griera, A., Jansen, D., Llorens, M.-G., Roessiger, J., and Weikusat, I.: Strain localization and dynamic recrystallization in the ice-air aggregate: a numerical study, The Cryosphere, 10, 3071-3089, https://doi.org/10.5194/tc-10-30712016, 2016.

Steinbach, F., Kuiper, E. N., Eichler, J., Bons, P. D., Drury, M. R., Griera, A., Pennock, G. M., and Weikusat, I.: Grain dissection: A new process for grain size reduction in polar ice cores and numerical models, Front. Earth Sci., in press, 2017.

Stocker, T., Dahe, Q., Plattner, G.-K., Tignor, M., Allen, S., and Midgley, P.: Workshop report of the intergovernmental panel on climate change workshop on sea level rise and ice sheet instabilities, available at: www.ipcc-wg1.unibe.ch/meetings/slrisi/slrisi. html (last access: 17 August 2017), 2010.

Suzuki, S.: Grain Coarsening of Microcrystals of Ice. (III), Low Temperature Science Ser. A, 28, 47-61, 1970.

Suzuki, S. and Kuroiwa, D.: Grain-boundary energy and grainboundary groove angles in ice, J. Glaciol., 11, 265-277, 1972.

Thoma, M., Grosfeld, K., Mayer, C., and Pattyn, F.: Interaction between ice sheet dynamics and subglacial lake circulation: a coupled modelling approach, The Cryosphere, 4, 1-12, https://doi.org/10.5194/tc-4-1-2010, 2010.

Trepied, L., Doukhan, J. C., and Paquet, J.: Subgrain boundaries in quartz theoretical analysis and microscopic observations, Phys. Chem. Miner., 5, 201-218, 1980.

Vaughan, D. and Arthern, R.: Why is it hard to predict the future of ice sheets?, Science, 315, 1503-1504, 2007.

Wei, Y. and Dempsey, J. P.: The motion of non-basal dislocations in ice crystals, Philos. Mag. A, 69, 1-10, 1994.

Wang, Y., Thorsteinsson, T., Kipfstuhl, S., Miller, H., Dahl-Jensen, D., and Shoji, H.: A vertical girdle fabric in the NorthGRIP deep ice core, North Greenland, Ann. Glaciol., 35, 515-520, 2002.

Wegner, A., Fischer, H., Delmonte, B., Petit, J.-R., Erhardt, T., Ruth, U., Svensson, A., Vinther, B., and Miller, H.: The role of seasonality of mineral dust concentration and size on glacial/interglacial dust changes in the EPICA Dronning Maud Land ice core, J. Geophys. Res.-Atmos., 120, 9916-993, 2015.

Wei, Y. and Dempsey, J. P.: The motion of non-basal dislocations in ice crystals, Philos. Mag. A, 69, 1-10, 1994.

Weikusat, C., Freitag, J., and Kipfstuhl, S.: Raman spectroscopy of gaseous inclusions in EDML ice core: First results microbubbles, J. Glaciol., 58, 761-766, 2012.

Weikusat, I., Kipfstuhl, S., Azuma, N., Faria, S. H., and Miyamoto, A.: Deformation Microstructures in an Antarctic Ice Core (EDML) and in Experimentally Deformed Artifcial Ice, in: Physics of Ice Core Records II. Vol. 2 of PICR, edited by: Hondoh, T., Vol. 68, 115-123, 2009a.

Weikusat, I., Kipfstuhl, S., Faria, S. H., Azuma, N., and Miyamoto, A.: Subgrain boundaries and related microstructural features in EPICA Dronning Maud Land (EDML) deep ice core, J. Glaciol., $55,461-472,2009 \mathrm{~b}$.
Weikusat, I., de Winter, D. A. M., Pennock, G. M., Hayles, M., Schneijdenberg, C. T. W. M., and Drury, M. R.: Cryogenic EBSD on ice: preserving a stable surface in a low pressure SEM, J. Microsc., 242, 295-310, 2010.

Weikusat, I., Miyamoto, A., Faria, S. H., Kipfstuhl, S., Azuma, N., and Hondoh, T.: Subgrain boundaries in Antarctic ice quantified by X-ray Laue diffraction, J. Glaciol., 57, 85-94, 2011.

Weikusat, I., Lambrecht, A., and Kipfstuhl, S.: Eigenvalues of crystal orientation tensors for c-axes distributions of vertical thin sections from the EDML ice core, https://doi.org/10.1594/PANGAEA.807142, 2013.

Weikusat, I., Kuiper, E.-J. N., Pennock, G. M., Kipfstuhl, S., and Drury, M. R.: EBSD analysis of subgrain boundaries and dislocation slip systems in Antarctic and Greenland ice, PANGAEA, https://doi.org/10.1594/PANGAEA.879614, 2017a.

Weikusat, I., Jansen, D., Binder, T., Eichler, J., Faria, S. H., Wilhelms, F., Kipfstuhl, S., Sheldon, S., Miller, H., DahlJensen, D., and Kleiner, T.: Physical analysis of an Antarctic ice core - towards an integration of micro- and macrodynamics of polar ice, Philos. T. R. Soc. Lond. A, 375, 20150347, https://doi.org/10.1098/rsta.2015.0347, 2017b.

Weertman, J. and Weertman, J. R.: Elementary Dislocation Theory, Oxford University Press, UK, 231 pp., 1992.

Wesche, C., Eisen, O., Oerter, H., Schulte, D., and Steinhage, D.: Surface topography and ice flow in the vicinity of the EDML deep-drilling site, Antarctica, J. Glaciol., 53, 442-448, 2007.

Wilhelms, F., Sheldon, S. G., Hamann, I., and Kipfstuhl, S.: Implications for and findings from deep ice core drillings - An example: The ultimate tensile strength of ice at high strain rates, Physics and Chemistry of Ice, The proceedings of the International Conference on the Physics and Chemistry of Ice held at Bremerhaven, Germany, 23-28 July 2006, 635-639, 2007.

Wilhelms, F., Miller, H., Gerasimoff, M. D., Drücker, C., Frenzel, A., Fritzsche, D., Grobe, H., Hansen, S. B., Hilmarsson, S. Æ., Hoffmann, G., Hörnby, K., Jaeschke, A., Jakobsdóttir, S. S., Juckschat, P., Karsten, A., Karsten, L., Kaufmann, P. R., Karlin, T., Kohlberg, E., Kleffel, G., Lambrecht, A., Lambrecht, A., Lawer, G., Schärmeli, I., Schmitt, J., Sheldon, S. G., Takata, M., Trenke, M., Twarloh, B., Valero-Delgado, F., and WilhelmsDick, D.: The EPICA Dronning Maud Land deep drilling operation Ann. Glaciol., 55, 355-366, 2014.

Wilson, C., Burg, J., and Mitchell, J.: The origin of kinks in polycrystalline ice, Tectonophysics, 127, 27-48, 1986.

Wolovick, M. J. and Creyts, T. T.: Overturned folds in ice sheets: Insights from a kinematic model of traveling sticky patches and comparisons with observations, J. Geophys. Res.-Earth, 121, 1065-108, 2016. 